\title{
A claim in search of evidence: reply to Manger's thermogenesis hypothesis of cetacean brain structure
}

\author{
Lori Marino $^{1 *}$, Camilla Butti ${ }^{2,3}$, Richard C. Connor ${ }^{4}$, R. Ewan Fordyce ${ }^{5}$, \\ Louis M. Herman ${ }^{6}$, Patrick R. Hof ${ }^{2}$, Louis Lefebvre ${ }^{7}$, David Lusseau ${ }^{8}$, \\ Brenda McCowan ${ }^{9}$, Esther A. Nimchinsky ${ }^{10}$, Adam A. Pack ${ }^{11}$, Joy S. Reidenberg ${ }^{12}$, \\ Diana Reiss ${ }^{13}$, Luke Rendell ${ }^{14}$, Mark D. Uhen ${ }^{15}$, Estelle Van der Gucht ${ }^{2}$, \\ and Hal Whitehead ${ }^{8}$ \\ ${ }^{1}$ Neuroscience and Behavioural Biology Program, Emory University, Atlanta, GA, USA \\ ${ }^{2}$ Department of Neuroscience, Mount Sinai School of Medicine, New York, NX, USA \\ ${ }^{3}$ Department of Experimental Veterinary Science, University of Padova, Italy \\ ${ }^{4}$ Department of Biology, University of Massachusetts, Dartmouth, North Dartmouth, MA, USA \\ ${ }^{5}$ Department of Geology, University of Otago, Dunedin, New Zealand \\ ${ }^{6}$ Department of Psychology, University of Hawaii at Manoa, HI, USA \\ ${ }^{7}$ Department of Biology, McGill University, Québec, Canada \\ ${ }^{8}$ Department of Biology, Dalhousie University, Nova Scotia, Canada \\ ${ }^{9}$ Department of Population Health and Reproduction, School of Veterinary Medicine, University of California, Davis, CA, USA \\ ${ }^{10}$ Department of Radiology, Mount Sinai School of Medicine, New York, Nr \\ ${ }^{11}$ The Dolphin Institute, Honolulu, HI, USA \\ ${ }^{12}$ Center for Anatomy and Functional Morphology, Mount Sinai School of Medicine, New York, NY, USA \\ ${ }^{13}$ Department of Psychology, Hunter College, CUNY, USA \\ ${ }^{14}$ Center for Social and Cognitive Evolution, Sea Mammal Research Unit, School of Biology, University of St Andrews, Fife, UK \\ ${ }^{15}$ Alabama Museum of Natural History, Tuscaloosa, AL, USA
}

(Received 9 October 2007; revised 12 June 2008; accepted 25 June 2008)

\begin{abstract}
In a recent publication in Biological Reviewes, Manger (2006) made the controversial claim that the large brains of cetaceans evolved to generate heat during oceanic cooling in the Oligocene epoch and not, as is the currently accepted view, as a basis for an increase in cognitive or information-processing capabilities in response to ecological or social pressures. Manger further argued that dolphins and other cetaceans are considerably less intelligent than generally thought. In this review we challenge Manger's arguments and provide abundant evidence that modern cetacean brains are large in order to support complex cognitive abilities driven by social and ecological forces.
\end{abstract}

Key words: brain, brain size, marine mammals, thermogenesis, intelligence, cognition, encephalisation, dolphin, cetacean, temperature.

\section{CONTENTS}

I. Introduction

II. Claim 1: cetacean brains enlarged in a "punctuated" evolutionary event when oceanic temperatures dropped during the Eocene-Oligocene transition

(1) The real test of the thermogenesis hypothesis is in the Eocene

(2) Homeostatic inconsistencies in Manger's thermogenesis hypothesis

* Address for correspondence: E-mail: lmarino@emory.edu 


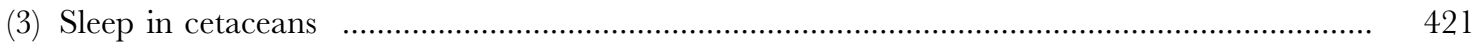

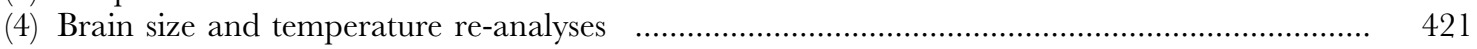

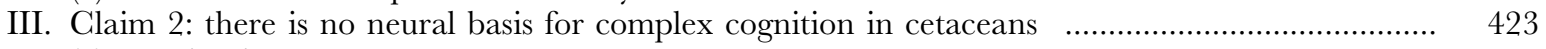

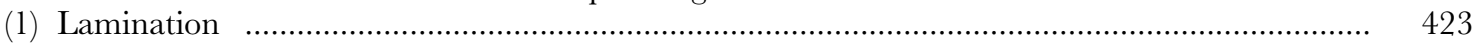

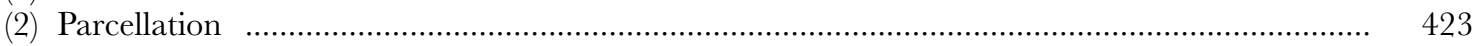

(3) Neuronal density, the glia/neuron index and the composition of the neuropil ....................... 424

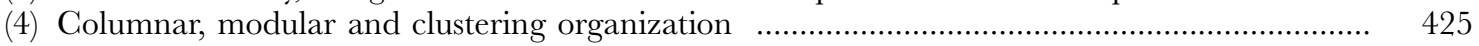

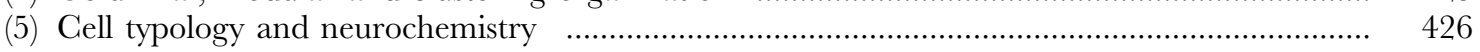

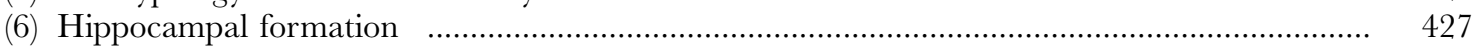

IV. Claim 3: there is no behavioural evidence for complex cognition in cetaceans .........................

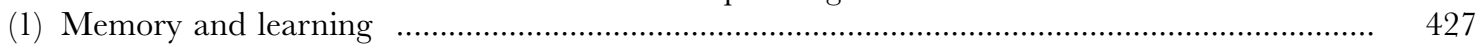

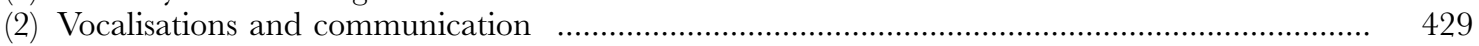

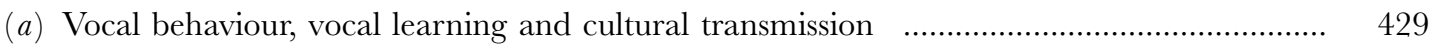

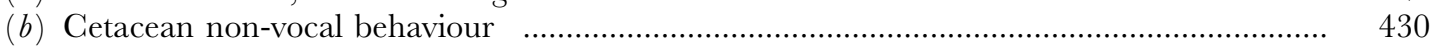

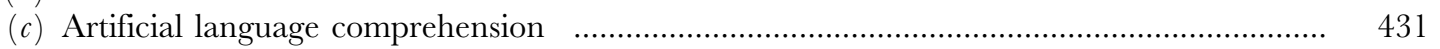

(3) Cognitive and social convergence with non-human primates $\quad$..................................... 431

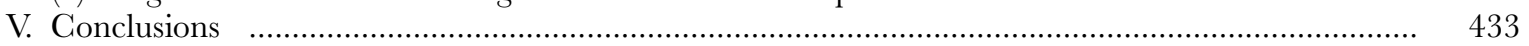

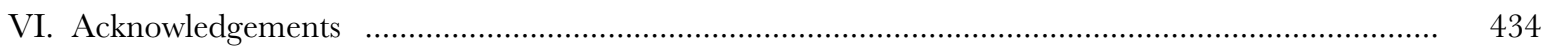

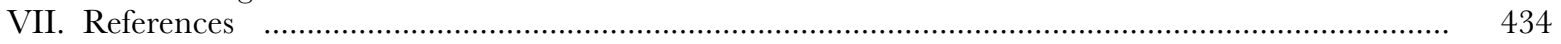

\section{INTRODUGTION}

Modern cetacean brains are among the largest of all mammals in absolute mass and in mass relative to body size. For instance, the sperm whale brain is approximately $60 \%$ larger than the largest non-cetacean brain, that of the elephant. Furthermore, odontocete (toothed whale), and particularly delphinid (dolphin), brains are significantly larger than the brains of any nonhuman primates and second only to humans in relative brain size measures (Marino, 1998). Thus, there has been a longstanding interest in the factors that influenced the evolution of cetacean brains. One current view of the evolution of dolphin brains is that their large size was primarily a response to social forces - the requirements for effective functioning within a complex society characterised by communication and collaboration as well as competition among group members (Connor, 2007; Connor, Smolker \& Richards,1992a, b; Herman, 1980). In such a society, individuals can benefit from recognition of others and knowledge of their relationships, and from flexibility in adapting or implementing new behaviours as the social or ecological context shifts. Other views focus on the cognitive demands associated with the use of echolocation in odontocetes (Jerison, 1986; Ridgway, 1986; Wood \& Evans, 1980). Regardless of what role each of these potential selective factors may have played in cetacean brain evolution the accepted general conclusion is that the large brain of cetaceans evolved in conjunction with complex cognitive abilities.

Recently, Manger (2006) made the controversial claim that cetacean brains are large because they contain an unusually large number of thermogenic glial cells whose numbers supposedly increased greatly to counteract heat loss during a decrease in ocean temperatures in the EoceneOligocene transition. Therefore, he claims the cetacean brain lacks the organisational structure necessary for complex information processing. These claims have garnered considerable attention in the popular press because they challenge prevailing knowledge and understanding of cetacean brain evolution, cognition and behaviour. Specifically, Manger (2006) makes three major assertions based on his interpretation of data in several areas of cetacean research: evolution and paleoecology, brain/body allometry, neuroanatomy, cognition, and behaviour. These claims are: 1) cetacean brains enlarged as a "punctuated" evolutionary event driven by a decrease in oceanic temperatures during the Eocene-Oligocene transition, 2) there is no neural basis for complex cognition in cetaceans, 3) there is no behavioural evidence for complex cognition in cetaceans.

Here we collectively respond to these three claims and show that each is seriously flawed. We produce evidence that invalidates each of Manger's claims and sustains the prevailing conclusion that cetacean brains became large to support complex cognitive abilities driven by social and ecological forces during cetacean evolution.

\section{GLAIM 1: CETACEAN BRAINS ENLARGED IN A "PUNGTUATED" EVOLUTIONARY EVENT WHEN OGEANIG TEMPERATURES DROPPED DURING THE EOCENE-OLIGOCENE TRANSITION}

Manger (2006, p. 317) describes the origin of large brains in cetaceans as an evolutionary "punctuation." He (p. 322) postulates that cetaceans evolved large brains in response to selection pressure from declining ocean temperatures during the Eocene-Oligocene transition. To support this hypothesis Manger (2006) summarises cetacean and oceanic history, largely without phylogenetic or stratigraphic detail, and, in so doing, misinterprets the data presented by Marino, McShea \& Uhen (2004a).

To address these issues, we first review relevant aspects of phylogeny. Odontocetes and mysticetes, which together comprise the Neoceti, evolved from basilosaurid 
archaeocetes late in the Eocene; the oldest named mysticete is Llanocetus ( $\sim 34.2$ million years ago [mya]), and the oldest named odontocete is Simocetus ( $32 \mathrm{Ma}$ ) (Fordyce, 2002b, $2003 b$ ). It is not known when precisely the Neoceti appeared, but Neoceti are at least as old as Llanocetus, and closely related archaeocetes are known from the same time (e.g. Chrysocetus, Uhen \& Gingerich, 2001). Another example is Saghacetus osiris, one of the geologically youngest "classic" archaeocetes which Manger (2006, pp. 314-315, his Fig. 11) discussed under the names Zeuglodon osiris, Z. sensitivus, and Z. elliotsmithi (see Gingerich, 1998, 439 for clarification). Archaeocetes and Neoceti clearly overlap in time, and archaeocetes did not disappear with the rise of Neoceti, but persisted at least until the Late Oligocene, $\sim 26 \mathrm{Ma}$ (Fordyce, 2002a). The Early Oligocene record (33.7-28.5 $\mathrm{Ma}$ ) of cetaceans is poor globally, with few described fossils (Fordyce, 2003a; Uhen \& Pyenson, 2007). Manger (2006) suggests that large brains in cetaceans arose circa the Early Oligocene as an evolutionary "punctuation," but there are no sequences of Early Oligocene fossils through which to track the tempo or mode of brain evolution, and thus claims about "punctuation" are not supportable at this point. However, many lineages of odontocetes and mysticetes are known from the Late Oligocene, 28.5-23.8 Ma (Fordyce, 2003a), implying a rapid, indeed explosive, earlier radiation of both odontocetes (raptorial echolocators) and mysticetes (bulk-filter feeders). Why, then, is the Early Oligocene record of cetacean fossils so sparse? A major global decrease in sea level about 29-30 Ma (Haq, Hardenbol \& Vail, 1987), possibly caused by growth of ice on Antarctica (DeConto \& Pollard, 2003; Lyle et al., 2007), is thought to have eroded away much of the global record of continental shelf sediments in which Early Oligocene cetaceans would have been found (Fordyce, 2003a, Uhen \& Pyenson, 2007). In short, because of the relative paucity of fossil data in the early Oligocene it is not possible to characterise the increase in relative brain size in odontocetes as punctuated or otherwise.

Early odontocetes were markedly smaller than putative archaeocete ancestors. Thus, as Marino et al. (2004a) found, the dramatic increase in relative brain size that occurred at the origin of Odontoceti resulted mainly from a significant decrease in body size, coupled with a modest increase in brain size, resulting in a substantial increase in relative brain size. Also, this description is only characteristic of the Odontoceti, as brain size trends in mysticetes have yet to be studied. Interestingly, odontocetes evolved during a lengthy period of cooling. Cooler climates have been linked with increases in body size (Bergmann's rule; e.g. Millien et al., 2006) because larger animals lose relatively less heat to the environment. This is not the case with odontocetes, who actually got smaller during that time. But importantly, the smaller odontocetes were still well above the minimum size needed for survival in a cool ocean (Downhower \& Blumer, 1988; Innes \& Lavigne, 1989). Therefore, there was no pressure for odontocetes to respond to these temperature decreases with either a change in body size or brain size. We conclude that changes in body size (and relative brain size) in odontocetes were due to factors other than the direct impact of oceanic cooling.

Manger's (2006, pp. 322-323) summary of cetacean evolution in relation to climate change needs clarification.
He alludes to supposedly warm water habits of archaeocetes, noting their distribution mainly in the equatorial Tethys Sea. Broader habits and tolerances are indicated, however, by the presence of archaeocetes in mid southern latitudes about 38$37 \mathrm{Ma}$ (Fordyce, 2003a). Further, the deep-sea temperature curve of Zachos et al. (2001, their Fig. 2) shows that oceans cooled steadily from $50 \mathrm{Ma}$ to $35 \mathrm{Ma}$, as archaeocetes diversified and spread out from the Tethys, before a sudden sharp Eocene-Oligocene drop about the time of origin of the Neoceti. There are caveats: the deep sea curve of Zachos et al. (2001) is widely accepted as an index of changing ocean climate and circulation, but it is a long-term global temperature curve which is not necessarily a proxy for surface water temperature at any one place. The scale of the Zachos et al. (2001) curve cannot show the predicted myriad of short-term orbitally-induced temperature fluctuations. Finally, latitudinal patterns must be considered. It is likely that tropical waters remained warm (Matthews \& Poore, 1980) throughout the history of cetaceans, and that changes indicated by the Zachos et al. (2001) curve reflect the development of ice at high latitudes and consequent changed temperature gradients from poles to tropics. The points made here are consistent with the hypothesis that cetacean evolution was not driven directly by climatic upset of homeostasis, but rather that climate change affected ocean circulation and food chains (Fordyce, 2003a), setting the scene for the Eocene-Oligocene radiation of the Neoceti.

Manger (2006) implies that the origin of large brains in odontocetes is linked to the "major cooling of oceanic temperatures" shown by Zachos et al. (2001) at 34-35 Ma, as addressed below, but cites Whitmore (1994) in support, and also implies a climate-forcing role for the closure of the Tethys sea as India and Africa sutured to Eurasia, citing Fordyce \& Barnes (1994). Whitmore (1994), however, only discusses climate change from $17 \mathrm{Ma}$ to present, long after the origin of Odontoceti (and Mysticeti). Fordyce \& Barnes (1994, p. 449) recognised the closure of the Tethys as a middle Eocene event affecting archaeocetes long before the Eocene-Oligocene cooling pulse and the origin of odontocetes. These misattributions and misrepresentations are surprising, given the wide literature on Eocene-Oligocene climate change and paleoceanography (see contributions in Prothero, Ivany \& Nesbitt (2003), and its relation to cetacean evolution (Fordyce, 2003a and references therein).

\section{(1) The real test of the thermogenesis hypothesis is in the Eocene}

It is an intriguing idea that oceanic temperature decrease was the selection pressure that drove the evolution of brain size in odontocetes. We have already discussed a number of problems with this thermogenesis hypothesis. We indicated above that Eocene-Oligocene temperature change was more complex than suggested by Manger (2006). To show further that the evidence does not match the prediction of the thermogenesis hypothesis, we now consider cetacean homeothermy, concluding that the Eocene-Oligocene cooling pulse probably had less direct impact on homeothermy than did the thermal stress encountered by cetaceans in their Early Eocene move from land to water. 
On thermal adaptation, Manger's (2006) reference (p. 318 ) on the insulative properties of blubber (Iverson, 2002) gives the thermal conductivity of water as 25 times that of air. Elsewhere, he (p. 314, 327) follows Downhower \& Blumer (1988), stating that heat loss in water is 90.8 times faster than in air at the same ambient temperature. However, actual heat loss in water, even for terrestrial mammals such as humans, is much lower. In a critique of Downhower \& Blumer (1988), Innes \& Lavigne (1989) gave the rate of heat loss by aquatic endotherms in water as only 1.6-4.5 times greater than in air. Smith \& Hanna (1975) reported studies of heat loss in water of humans, citing a range of water/air conductance ratios from 2.30 to 4.45 for the heaviest and lightest subjects, respectively, and a mean conductance ratio (water/air) of 3.34. If one were to predict a change in brain size due to the need for thermogenesis in a new aquatic environment, one would expect to see it at the change from a terrestrial to an aquatic environment, not at the change from the relatively warm Eocene ocean to the relatively cool Oligocene ocean. This change is demonstrably absent at the transition from either the terrestrial pakicetids to the semi-aquatic protocetids, or from the protocetids to the fully aquatic basilosaurids. And, as previously stated, even the smallest juvenile cetaceans were well above the threshold for heat loss described by Downhower \& Blumer (1988) making the issue of selection for increased brain size moot.

The most plausible explanation for the change in brain/ body allometry in odontocetes is that cooling in temperate to polar latitudes (Zachos et al., 2001) led to oceanic trophic changes and ultimately the evolution of a new echolocating niche for some Cetacea. Cooling-induced changes in oceanic current systems triggered changes in diversity and productivity in oceanic food chains as revealed by evidence for increases in productivity close to the Eocene/Oligocene boundary in the Southern Ocean (Salamy \& Zachos, 1999). Odontocetes, with their new echolocation-assisted hunting strategy, evolved at this time of changing oceanic ecology (Fordyce, 2003a; Lindberg \& Pyenson, 2007). The initial moderate increase in odontocete brain size is matched by changes in cranial architecture including the evolution of the novel echolocation-related nasofacial muscle complex (Fordyce, 2002b, 2003a), and there is evidence of concurrent change in ear structure associated with echolocation (Fleischer, 1976). Thus the large brains of early odontocetes were likely used, at least partly, for processing an entirely new sensory mode. Additionally, the decrease in body size may have driven changes in behavioural ecology (foraging and predation risk, for instance see Lindberg \& Pyenson, 2007). It is likely that the enlarged brain was used for integrating echolocation information into an increasingly complex behavioural ecological system.

\section{(2) Homeostatic inconsistencies in Manger's thermogenesis hypothesis}

Manger's (2006) thermogenesis hypothesis is inconsistent with what is known about mammalian homeostatic mechanisms. First, he (p. 314) suggests that unihemispheric sleep and the small amount of rapid-eye-movement (REM) sleep in cetaceans are responsible for an increase in firing of noradrenaline-secreting neurons, producing high levels of noradrenaline in the brain. He then concludes that "[a] high percentage of glia and a consistent metabolic influence of noradrenaline, would suggest that the brain of the cetacean is likely to be a proficient thermogenesic organ" (p. 314). However, biological systems are regulated by multiple dynamic equilibrium adjustments such as the adaptation of the brain to changes in neurotransmitter levels by up- or down regulation of receptors over the course of minutes or days. Adaptive changes to catecholamine levels in particular are well documented (Reisine, 1981; Schwartz et al., 1978; Sutin \& Minneman, 1985) and adaptation to changes in noradrenaline levels have been reported in the mouse brain (Magistretti, Hof \& Celio, 1987) and are mentioned in Stone \& Ariano (1989), an article that Manger (2006) quotes on p. 314. Thus, the chronic presence of high levels of noradrenaline in the cetacean brain would likely be followed by an adaptive process with a consequent decrease of sensitivity to this substance, and not by a sustained state of increased excitability extending not only over minutes or hours, but through millions of years of evolution.

Second, Manger (2006) claims that high levels of noradrenaline lead to increases in astrocyte metabolic rate and consequently additional heat production in the brain. However, whereas the noradrenergic system influences glial metabolism, it does not necessarily follow that an increase in metabolic rate generates heat, and enough heat to implicate astrocytes as major players in temperature regulation. Manger's (2006) argument is an empirical quantitative argument that should be addressed by data or by computational techniques. Yet he provides no such evidence. This is quite surprising, given that the biochemical pathways and their energetic dynamics are currently understood well enough in a quantitative manner to permit at least some rudimentary modeling.

Moreover, Manger (2006) does not consider several aspects of an increased metabolic rate of astrocytes which would play a role in this context. There is considerable evidence of neuron-glia metabolic 'cooperation' in the lactate shuttle hypothesis (Magistretti \& Pellerin, 1999; Pellerin, 2003; Pellerin \& Magistretti, 2004). This hypothesis suggests astrocytes respond to synaptic activity with glutamate uptake and thus increase their rate of anaerobic glycolysis and lactate production. Lactate is then used by neurons as a preferential oxidative energy substrate (Bouzier-Sore et al., 2003). In this context, to be convincing, Manger's (2006) thermogenesis hypothesis not only should explain the qualitative and quantitative details of heat production by astrocytes but should also consider that the products of astrocytic metabolism, such as lactate, might become a limiting factor at cold temperatures, as the brain manages the effect of lactate on its tightly regulated $\mathrm{pH}$.

Third, Manger (2006) does not provide any empirical support for the assumption that heat in the brain is produced specifically by astrocytes. In fact, although there is evidence of the possible dissipation of energy as heat in nervous tissue due to the role of uncoupling proteins (Erlanson-Albertsson, 2003; Mao et al., 1999; Yu et al., 
2000), it is not clear whether it is neurons, astrocytes, or both cell types that express these proteins.

Fourth, it should also be noted that Manger (2006) refers to a "high proportion of glial cells in the cetacean cerebral cortex" (p. 310) without discriminating among oligodendrocytes, astrocytes, and microglia, which have very different functions and influences on brain energy metabolism as a whole. Oligodendrocytes are responsible for the synthesis of the myelin sheath. They have been shown to use lactate as a substrate for both energy metabolism and lipogenesis and they have a higher metabolic rate than neurons and astrocytes (Sanchez-Abarca, Tabernero \& Medina 2001). Thus, the lactate produced and released by astrocytes is metabolised by both neurons and oligodendrocytes. Oligodendrocytes may have a role in Manger's (2006) theory but he does not address this. What he proposes involves only astrocytes; the relative contribution of astrocytes and oligodendrocytes to the purported high glia/neuron index is not considered by Manger (2006), which in itself weakens the claim of its role in cetacean brain homeostasis.

Fifth, Manger (2006) does not deal with one particularly problematic consequence of his theory: the decrease of heat exchange at the capillary level that would be driven by the reduced temperature gradient caused by the warm astrocytes enveloping blood vessels. In the dolphin the blood vessels of the brain are surrounded by astrocytic endfeet (Glezer, Jacobs \& Morgane, 1987; Pritz-Hohmeier et al., 1994) as in other mammals (Peters, Palay \& Webster, 1991). It is reasonable to assume that the vascular system here plays the same temperature-moderating role in homeostasis as in other mammals.

Sixth, adaptations, such as blubber, the rete mirabile (see below), and a highly efficient counter-current heat exchange system, probably evolved early, not late, in cetacean history (Uhen, 2004). Moreover, it cannot be argued that known cetacean mechanisms of thermoregulation regulate body temperature to the exclusion of the brain. Cerebrospinal fluid is filtrated from blood, and is equally warm. Cold water is a challenge to the entire body of the whale, and its adaptations serve the entire organism.

In this context, it is odd that Manger (2006) does not mention the classic role of the vasculature in the regulation of brain (and body) temperature (Hayward \& Baker, 1969) and the evidence for the more pressing need to cool rather than heat the brain (Caputa, 2004; Zenker \& Kubik, 1996). Specifically, Manger (2006) does not mention the extremely specialised cerebrovascular blood supply that cetaceans possess. In cetaceans, the blood supply to the brain is derived entirely from an extremely well-developed thoracospinal rete mirabile as internal carotid and vertebral arteries do not play any role in brain vascularisation (McFarland, Jacobs \& Morgane, 1979). Several functions have been proposed for the rete mirabile system in cetaceans. In their authoritative paper on the cetacean cerebrovascular supply system McFarland et al. (1979) provide evidence from the work of Nakajima (1961) of a high proportion of veins in both odontocete and mysticete retia, with the exception of the thoracic rete. They also discuss evidence from Slijper $(1936,1958)$ that spinal veins are the most important route of venous return from the cetacean brain. Furthermore,
Pfeiffer \& Kinkead (1990, p. 141) described brain retia as composed of "branched small arteries, veins, or of mixed composition". Such evidence leads one to wonder whether the retia in cetaceans may have a role in thermoregulation as already described for the counter-current heat exchange system, a specialisation described in odontocetes (Rommel et al., 1992; Scholander \& Schevill, 1955), mysticetes (Heyning \& Mead, 1997), sirenians (Rommel \& Caplan, 2003), and phocids (Rommel et al., 1995). In the counter-current heat exchanger, the major arteries entering the fins, flippers and fluke are surrounded by a venous channel (Scholander \& Schevill, 1955) and, depending on the blood flow velocity, this system allows for either maximal heat conservation or maximal cooling of the body as well as thermoregulation of target organs (Rommel et al., 1992, 1995). Given this precedent, a thermoregulatory function of the rete mirabile would be less exotic and more plausible than the recruitment of glial cells for this purpose. Given the impressive efficiency of the vascular system in regulating body temperature throughout the cetacean body, the burden is on Manger to demonstrate that this existing system would be inadequate to maintain brain temperature as well.

\section{(3) Sleep in cetaceans}

Manger (2006) infers from a set of unrelated studies (Lyamin et al., 2002; Mukhametov, 1995; Stone \& Ariano, 1989), that REM sleep might be associated with a cooling of the brain. Thus, he claims that the very small amount of REM sleep, if any, in cetaceans is direct support for his "thermogenesis hypothesis". Here, again, Manger (2006) does not provide supporting evidence for his claim. More importantly, numerous studies (reviewed in Wehr, 1992, but not cited by Manger, 2006) provide direct contrary evidence. Wehr (1992) reports that increases in the central nervous system temperature during REM sleep have been observed in rats (Alföldi et al., 1990; Schmidek, Zachariassen \& Hammel, 1983), cats (Hayward \& Baker, 1969; Parmeggiani et al., 1984), sheep (Hayward \& Baker, 1969), rabbits (Hayward \& Baker, 1969; Kawamura \& Sawyer, 1965; Kawamura, Whitmeyer \& Sawyer, 1966), and squirrel monkeys (Edgar \& Furrel,1984) and that there is indirect evidence of an increase in brain temperature during REM sleep in humans (Palca, Walker \& Berger,1981). The available data thus do not support a REM-associated cooling of the brain.

\section{(4) Brain size and temperature re-analyses}

Even without the myriad of theoretical, mechanistic, and empirical flaws in Manger's (2006) arguments described above, there still remains a basic question about the quality of the specific analyses Manger (2006) used to test the relationship between thermoregulation and brain size. There are numerous fatal flaws in his analyses. First, the temperature range data used in his Table 1 are often incorrect. Indeed, these values are even in disagreement with the examples he gives in his Fig. 16. For example, in his Fig. 16 Balaenoptera musculus and Megaptera novaeangliae range from polar to tropical waters (which they do) giving them 
a temperature range in excess of $27^{\circ} \mathrm{C}$, yet in Table 1 they are reported to have a temperature range of -1 to $+5^{\circ} \mathrm{C}$. We list these errors and our corrections in our Table 1. Also, Manger (2006) does not include temperature data for two further species (fin whale, Balaenoptera physalus and killer whale, Orcinus orca) in his analysis although the information is readily available. B. physalus is found in the Ligurian Sea during the summer where temperatures can reach $27^{\circ} \mathrm{C}$, as well as the polar ice edges $\left(-1^{\circ} \mathrm{C}\right)$ giving a temperature range of $28^{\circ} \mathrm{C}$. $O$. orca is found from the equator to the ice edge, from -1 to $29^{\circ} \mathrm{C}$, giving a temperature range of $30^{\circ} \mathrm{C}$. The distributional information used to make these corrections is well summarised by Reeves et al. (2002), as well as being recorded personally by several of the present authors. We repeated the regression of habitat temperature range on encephalization quotient (EQ) that Manger (2006) used to suggest a relationship between brain size and thermal buffering needs, using the corrected temperature range values, and found no significant relationship between the two. In fact, there is a negative trend, the opposite of that claimed by Manger (2006) (compare our Fig. 1 with Fig. 15 in Manger, 2006), thus eliminating a critical component of his argument.

Manger used EQ(Jerison, 1973) as the metric of relative brain size in these correlational analyses. In cetaceans, EQ derived from a class-level equation is negatively correlated with log body size (Marino et al., 2006), which is also the case in Manger's (2006) data set on extant $(r=-0.768, \mathrm{~N}=$ $34, \mathrm{P}<0.001)$ and fossil $(r=-0.701, \mathrm{~N}=56, \mathrm{P}<0.001)$ species. When we factor in body weight in multiple regressions, the partial correlations between EQ and minimum or maximum temperature fail to reach significance whether we use Manger's incorrect temperature data or the corrected ones referred to above (EQ with Manger's data on minimum temperature: partial $r=-0.209, \mathrm{P}=$ 0.306; on maximum temperature: partial $r=0.024, \mathrm{P}=$ 0.909; with corrected data on minimum temperature: partial $r=-0.349, \mathrm{P}=0.069$; with corrected data on maximum temperature: partial $r=0.165, \mathrm{P}=0.392)$. Instead, body size is the only variable that is significantly associated with temperature in three of the four multiple regressions (with Manger's data on minimum temperature: partial $r=-0.469, \mathrm{P}=0.014$; on maximum temperature: partial $r=-0.697, \mathrm{P}<0.001$; with corrected data on minimum temperature: partial $r=-0.618, \mathrm{P}<0.001$; with corrected data on maximum temperature: partial $r=$ $-0.100, \mathrm{P}=0.604)$. Neither maximum nor minimum temperature, whether taken from Manger's Table 1 or corrected, correlate with residual brain size (log brain size regressed against log body size), a standard measure of brain size that is not confounded by body size when the regression is conducted at the level of the order (Marino et al., 2006).

Aside from EQ, Manger uses two corticalisation indices (CI) to argue his case against the cognitive interpretation of cetacean brain size. Like EQ, however, the two indices are confounded by body size, so we cannot tell if it is the corticalisation differences or the body mass differences that are driving the observed trends. CI1, the ratio of cortical volume divided by brain volume, is positively correlated with body mass $(r=0.686, \mathrm{~N}=86, \mathrm{P}<0.001)$. CI2, the ratio of grey matter volume divided by brain volume, has a relationship that goes in different directions for cetaceans versus other mammals. For cetaceans, the data show a strong negative relationship with body size $(r=-0.801, \mathrm{~N}=9, \mathrm{P}=$ 0.009), which is opposite to the positive one for CIl. For other mammals, the relationship is strongly positive $(r=$ 0.656, $\mathrm{N}=16, \mathrm{P}=0.006$ ).

To summarise, there are two major flaws in Manger's (2006) analyses of the relationship between brain size and temperature. First, the temperature data he used contain incorrect values and do not take into account all of the temperature data available. Second, he uses EQ in a statistically inappropriate way. When his statistical analyses are redone with the correct available temperature data and the correct measure of relative brain size there is no relationship between temperature and brain size. Given that this postulation forms the foundation of Manger's (2006) entire argument, these re-analyses show that Manger's (2006) major argument is unfounded.

Table 1. Corrected habitat temperature range data presented in Manger (2006)

\begin{tabular}{|c|c|c|c|}
\hline $\begin{array}{l}\text { Species and temp. range } \\
\left({ }^{\circ} \mathrm{C}\right) \text { given in Manger }(2006)\end{array}$ & Temp. range (correct) & $\begin{array}{l}\text { Old range / } \\
\text { New range / } \\
\text { Difference }\end{array}$ & Comments \\
\hline P. macrocephalus (15-23) & $0-29$ & $8 / 29 /+21$ & $\begin{array}{l}\text { Commonly found in waters down to } 0^{\circ} \mathrm{C} \\
\text { (for example off west Greenland and near } \\
\text { the ice edge in Antarctica), as well as up to } \\
29^{\circ} \mathrm{C} \text { (e.g. western tropical Pacific). }\end{array}$ \\
\hline T. truncatus (13-29) & $2-29$ & $16 / 27 /+11$ & $\begin{array}{l}\text { Found in waters down to } 2^{\circ} \mathrm{C} \text { in New Zealand } \\
\text { fjords in winter. }\end{array}$ \\
\hline E. robustus $(-1-4)$ & $-1-17$ & $5 / 18 /+13$ & $\begin{array}{l}\text { Found very commonly in waters up to } 17^{\circ} \mathrm{C} \text { off Mexico, } \\
\text { where they give birth in coastal lagoons. }\end{array}$ \\
\hline B. borealis $(2-8)$ & $2-18$ & $6 / 16 /+13$ & $\begin{array}{l}\text { Common on edge of the Scotian Shelf in summer } \\
\text { in temperatures up to about } 18^{\circ} \mathrm{C} \text {. }\end{array}$ \\
\hline B. musculus $(-1-5)$ & $-1-27$ & $6 / 28 /+22$ & Common off Sri Lanka, where temperatures reach $27^{\circ} \mathrm{C}$ \\
\hline M. novaeangliae $(-1-5)$ & $-1-23$ & $6 / 24 /+18$ & $\begin{array}{l}\text { Very common in the Caribbean in winter in } \\
\text { temperatures up to } 23^{\circ} \mathrm{C} \text {. }\end{array}$ \\
\hline
\end{tabular}




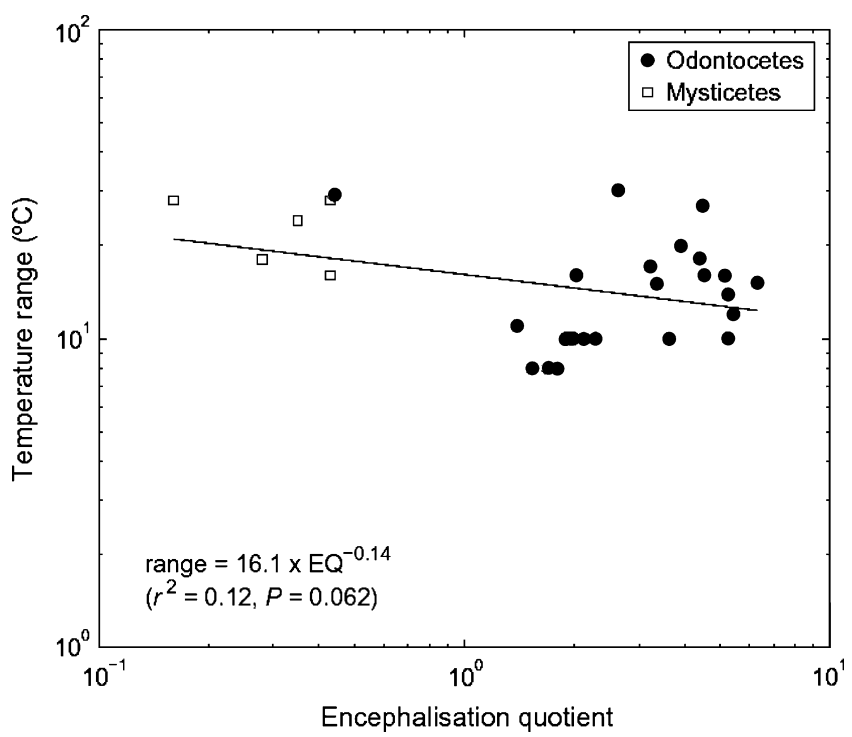

Fig. 1. Plot of habitat water temperature range against encephalisation quotient (EQ), using corrected temperature range data. There is no significant relationship between the two variables: the trend is opposite to that claimed in Manger (2006). Except where corrected (see text and Table 1 for details), data are from Table 1 in Manger (2006).

\section{CLAIM 2: THERE IS NO NEURAL BASIS FOR COMPLEX GOGNITION IN GETAGEANS}

Modern cetaceans and primates both have extraordinarily high relative brain sizes, despite the fact that the two groups diverged from a common ancestor over 95 million years ago (Kumar \& Blair Hedges, 1998) and derived these high encephalisation quotients completely independently. During that time cetacean brains evolved a unique combination of features that are different in many respects from primate brains. These differences are the most compelling aspect of cetacean brains, which in all likelihood represent a nonprimate route to neuroanatomical (and cognitive) complexity.

Manger (2006, p. 294) states that "The belief in the apparently undeniable high level of intelligence is derived from two features of the cetaceans, one morphological and the other behavioural". In the following section we will further describe and discuss the morphological features of the cetacean cortex and argue that there is indeed strong evidence of a neural basis for complex cognition in cetaceans.

\section{(1) Lamination}

The general lamination pattern of the cetacean neocortex is characterised by a thick, cellular layer I, a densely packed layer II containing extraverted neurons with dendrites extending into layer I, a wide pyramidal layer III, an absent or underdeveloped layer IV, a magnocellular layer $\mathrm{V}$ with large pyramidal cells, and a heterogeneous layer VI (Glezer \& Morgane, 1990; Hof, Chanis \& Marino, 2005; Hof \& Van der Gucht, 2007; Morgane, Glezer and Jacobs, 1988). The findings of Glezer and Morgane (1990) on synaptic distribution in the cetacean neocortex highlight the peculiar organisation of this laminar pattern in which layer I possibly represents the main target for subcortical afferent neurons, owing to the absence of layer IV, whereas layer II may relay information from layer I afferents to the lower cortical layers. Thus, the general lamination pattern exhibited by the cetacean neocortex reflects a very different connectivity scheme compared to more commonly studied species, like rats and macaque monkeys. These particular arrangements of layers, with the drastic reduction of layer IV as an input layer, may have involved a reorganisation of the neocortex into a thinner and deeply convoluted structure.

Although the organisation of the cetacean neocortex still retains regions of less differentiated lamination, several recently described features of both the odontocete and mysticete neocortex point to the neocortical complexity and variability in these mammals (Hof et al., 2005; Hof \& Van der Gucht, 2007). Thus, the three "points of interest" that Manger (2006, p. 303) gives regarding the indistinct lamination of the cortex, the pyramidalization of layer II and the absence of layer IV, are just one aspect of the unusual combination of (elaborated) conservative and derived features that characterise the complexity of cetacean neocortex.

\section{(2) Parcellation}

Regarding the parcellation of the cetacean cerebral cortex Manger (2006, p. 305) concludes that: "There does not appear to be a prefrontal cortical region; the number of the subdivisions of the cortex appears to be low compared with other mammals with similarly sized brains or even mammals with far smaller brains; the temporal cortical region is small and undeveloped; and the limbic region of cortex, or cingulate cortex, is small, especially in its anterior aspect". This statement is not consistent with anatomical evidence.

Although there is no reason to expect that, given their long and highly divergent evolutionary histories and different morphological arrangements, cetacean and primate prefrontal cortical homologues would be located in the same region of the brain, it remains that the frontopolar region of the cetacean brain includes a large expansion of cortex and is histologically distinct from the motor and somatosensory cortices located dorsal to it. In addition, this region is characterised by a variable cytoarchitecture indicating the presence of a number of cortical subregions (Hof et al., 2005; Hof \& Van der Gucht, 2007). If the primate frontal cortex can be subdivided into many regions, some having a well-known function, the histological findings in cetaceans offer no reason to suspect that a similar degree of functional complexity could not exist in these species. Albeit the orbitofrontal cortex does contain domains that appear to be less "differentiated", especially in its posterior aspects, any observer of the human brain will not miss the fact that a comparable cytoarchitectural trend occurs as one proceeds posteriorly. The possible homologue of the orbitofrontal cortex in cetaceans is notably very large. 
Furthermore it is unclear why Manger (2006) alleges that the anterior cingulate cortex in cetaceans is small. It is located ventral to the limbic cleft and is characterised by a highly sulcated, large amount of tissue, especially around the genu of the corpus callosum, presenting with many distinguishable subdomains along two intercalate sulci that may find an equivalent in the paracingulate sulcus, a highly variable feature observed, interestingly, only in the human brain (Jacobs, McFarland \& Morgane, 1979; Morgane, Jacobs \& McFarland, 1980; Ono, Kublik \& Abernathy, 1990). Morgane and collaborators have presented detailed descriptions of its histological complexity in their classic papers on the bottlenose dolphin (Tursiops truncatus) (Jacobs et al., 1979; Morgane et al., 1980) and similar observations were recently made for the humpback whale (Megaptera novaeangliae) by Hof and Van der Gucht (2007). Indeed, the cingulate gyrus has been previously described as "extremely well developed" in different odontocete species by different authors (Breathnach \& Goldby, 1954; Jacobs et al., 1979) and Hof \& Van der Gucht (2007) confirmed the presence of "complex and extensive" cingulate and insular cortices in the humpback whale. The expansion of the insular and cingulate cortices in cetaceans is consistent with high-level cognitive functions: attention, judgment, intuition, and social awareness and known to be associated with these regions in primates (Allman et al., 2005; also see Marino et al., 2004b). Moreover, the anterior cingulate and the insular cortices are two select areas in which, in largebodied cetaceans, a unique type of projection neuron has been observed, known as the spindle cell or Von Economo neuron, that has been related to complex cognitive function in humans and great apes (Allman et al., 2005) (see Section III. 5).

Finally, several cytoarchitectural analyses reveal the existence of a clear regional parcellation in cetaceans comparable to cortical hierarchies in primates and carnivores in the parietal and temporal opercular regions (Felleman \& Van Essen, 1991; Glezer et al., 1993; Glezer, Hof \& Morgane, 1998; Hof et al., 1992, 2000, 2005; Hof \& Van der Gucht, 2007; Scannell, Blakemore \& Young, 1995). The cortical organisation in both odontocetes and mysticetes is mainly based on a common scheme but specific cytoarchitectural differences are evident between the two suborders and among species belonging to the same family. These cytoarchitectural differences appear to reflect functional organisation and, again, point to the exquisite specialization of the brain in these aquatic mammals.

Finally, Manger (2006, p. 332) states that " the anatomy of the acoustic system demonstrates that while it is specialised, this is to a similar degree as specialised sensory systems in other mammals with standard brain sizes and therefore cannot be a contributing factor to increased relative brain size".

This statement is unsubstantiated because there is a lack of direct experimental data in cetaceans. In echolocating cetaceans it is well known that the acoustic structures of the brainstem and thalamus are considerably increased in size (Glezer et al., 1998), contributing to an increase in the relative size of these brain segments. In most cetacean species the brain shows a massive extension of temporoparietal cortex that is unlike that in any other species (Hof et al., 2005; Hof \& Van der Gucht, 2007). The issue is that in spite of evidence for a high diversity of cytoarchitectural features in these cortical regions we simply do not have enough direct evidence to determine the functional significance of the sizes of different brain areas in cetaceans. Therefore, with no such evidence, Manger's (2006) contention remains ungrounded.

\section{(3) Neuronal density, the glia/neuron index and the composition of the neuropil}

At the core of Manger's (2006) argument is the apparent observation that cetacean brains have a glia/neuron $(\mathrm{G} / \mathrm{N})$ index that is higher than expected. In this section we will demonstrate that the extant data simply do not support this observation, and therefore that this argument, and by extension, the thesis of Manger (2006), is baseless. However, since in the course of his discussion numerous other issues arose which call for discussion, we will also address each of these in turn, even though the validity of the initial argument does not hinge upon them.

First it is important to note that, in contrast to the data on brain and body size or encephalisation, data on cell types in cetaceans, and indeed in other mammals, are relatively sparse. They are not, however, quite as sparse as one would assume based on Manger's discussion (see his Section III. 6). In fact, there are data from rodents (Ren et al., 1992) and even from cetaceans (Blinkov \& Glezer, 1968; Gihr \& Pilleri, 1969; Kraus \& Pilleri, 1969) that greatly contribute to this discussion, and it is unfortunate that Manger did not avail himself of them. As such, his contention that cetaceans are outliers in the G/N-brain volume curve is based solely on his extension of data from insectivores to cetaceans. The assumption, then, is that insectivores represent the norm, and cetaceans are the outliers, a supposition that is very difficult to support, since neither Order can be described as being "typical" for the Class. Insectivores are highly conserved, and cetaceans highly derived - both are probably outliers within Mammalia.

Second, on the basis of three studies (Garey \& Leuba, 1986; Hawkins \& Olszewski, 1957; Reichenbach, 1989), Manger (2006, p. 310) concludes that ". . it appears that the cetacean cerebral cortex has a substantially higher proportion of glia than is found in other mammals". This is a misinterpretation of the available data. Manger (2006, p. 310) refers to Fig. 3 of Reichenbach (1989, p. 75) as showing "the allometric relationship" between the G/N ratio and the thickness of the cerebral cortex. This figure is a crude schematic, not a nomogram, and cannot be used for quantitative measurements. More importantly, in Stolzenburg. Reichenbach \& Neumann (1989, Fig. 7B, p. 82), the correlation between the $\mathrm{G} / \mathrm{N}$ index and the brain tissue thickness (which can be either thickness of the total brain wall from ventricle to pia, total cortical thickness or thickness of the cortical layers) is shown only in five insectivore species (etruscan shrew, Suncus etruscus; pygmy shrew, Microsorex hoyi; european mole, Talpa europaea; checkered elephant shrew, Rhynchocyon cirnei; and giant otter shrew, Potamogale velox) and not in a wide range of mammals, and none of them 
cetaceans. The "other mammals" in the above quote, are thus actually all insectivores, a highly conserved subgroup of the mammalian class. It is worth noting that none of the species used to define the relationship between $\mathrm{G} / \mathrm{N}$ index and brain tissue thickness possess a convoluted brain; as Stolzenburg et al. (1989) argue, an estimate of brain wall thickness can be reliably obtained "only in agyral cortices". Since the cetacean cortex is anything but agyral there are no reliable estimates of this variable for cetaceans. The relationship between brain tissue thickness and $\mathrm{G} / \mathrm{N}$ index remains valid only for the insectivore species studied by Stolzenburg et al. (1989). It must still be demonstrated that this relationship, as intriguing as it is, holds true for other mammals, such as rodents, carnivores, lagomorphs, primates or cetaceans.

Third, it is difficult to reach meaningful conclusions on the $\mathrm{G} / \mathrm{N}$ index of cetaceans when comparing data obtained with different techniques (Garey \& Leuba, 1986; Hawkins \& Olszewski, 1957; Reichenbach,1989). The best method for obtaining quantitative data on cell populations is stereology that allows for unbiased population estimates. To our knowledge, a G/N index of 7.7/1 reported by Eriksen \& Pakkenberg (2007) in the minke whale, Balaenoptera acutorostrata, neocortex is the only published quantitative estimate obtained in the cetaceans using a reliable technique. Using the same stereological approach, we have estimated a $\mathrm{G} / \mathrm{N}$ index of $5.7 / 1$ in the anterior cingulate cortex of a beluga whale (Delpinapterus leucas, C. Butti \& P.R. Hof, unpublished data). This value is comparable with those obtained by Eriksen \& Pakkenberg (2007) and reflects the expectation of a lower value of this parameter in odontocetes than in mysticetes. Thus, there is no evidence that $\mathrm{G} / \mathrm{N}$ index is disproportionately higher in cetaceans than in other mammals, since there are few such studies using similar techniques in other orders. As such, until reliable and comparable data become available, no meaningful conclusions can be drawn comparing the $\mathrm{G} / \mathrm{N}$ index between cetaceans and other mammals.

Fourth, with respect to the space occupied by neuropil in the cetacean brain Manger (2006) states ". . .there appears to be a high proportion of glial cells in the cetacean cerebral cortex. It is therefore reasonable to assume that glial processes occupy a greater proportion of the neuropil in cetaceans than in other mammals" (p. 310), "... a high density of myelinated axons indicates that a higher proportion of the neuropil is occupied by myelin sheaths" (p. 310), "...the observed higher proportion of glial processes, myelin sheaths and axons of passage" without showing any data in support of such statements. It is particularly disturbing that, given the morphological differences between cetacean and other mammalian neurons to which Manger (2006) devotes considerable discussion (p.306-307), he does not seem to consider the possibility that glial cells, too, might differ considerably among these species. Indeed, Manger's inference that the larger neuropil in cetaceans is occupied by glial processes rests on the assumption that glial processes in cetaceans behave the same way as those in other mammals. Until reliable data on the $\mathrm{G} / \mathrm{N}$ ratio, axonal length and degree of dendritic arborisation, and glial morphology are available for cetacean brains, any assumption on the proportion of neuropil occupied by axons, dendrites, spines, glial processes and myelin sheaths is without basis.

Manger (2006, p. 310) states that the "cerebral cortex of cetaceans stains heavily for myelin"; this is not direct evidence that the cetacean cortex is more myelinated than that of other mammals and certainly may not be used as evidence to support the bold claim (p. 311) that the cetacean cortex "... may not be optimally wired." Axonal diameter in the bottlenose dolphin optic nerve has been reported to be up to $15 \mu \mathrm{m}$ with a mean of $11 \mu \mathrm{m}$ (Dawson et al., 1982) and additional estimates are available for the genual and splenial area of the corpus callosum where the average axonal diameter is $5.05 \mu \mathrm{m}$ and $5.54 \mu \mathrm{m}$, respectively, in the bottlenose dolphin, $4.86 \mu \mathrm{m}$ and 4.92 $\mu \mathrm{m}$ in the humpback whale, $3.87 \mu \mathrm{m}$ and $4.13 \mu \mathrm{m}$ in the harbor porpoise (Phocoena phocoena), and $3.98 \mu \mathrm{m}$ and 4.08 $\mu \mathrm{m}$ in the striped dolphin (Stenella coeruleoalba) (Hof, unpublished data). Although comparable data on other mammals are not available, we can speculate that the combination of a large number of neocortical neurons (Eriksen \& Pakkenberg, 2007) and a high conduction velocity due to the presence of large myelinated axons (reviewed in Hartline \& Colman, 2007) may actually place the cetacean brain into a privileged condition for complex information-processing capacities.

Finally, Manger (2006, p. 310) points out that several studies reported a low neuronal density in the cetacean brain. This observation simply confirms expectations for large mammalian brains. In fact, as earlier hypothesised, there is an inverse relationship between brain size and neuronal density (Poth et al., 2005; Tower, 1954). Data reported by Manger (2006) himself (p.310) show that the neuronal density in the mammalian brain tends to decrease with an increase in brain size, with Homo sapiens having a lower neuronal density than small mammals. As such, the low neuronal density observed in the cetacean brain is not a unique feature of these aquatic mammals but rather a common feature of big-brained species. On p. 332 Manger (2006) concludes that a "low number of neurons" and other features that he attributes to the cetacean brain "will all impact negatively on the processing capacity of the cerebral cortex". This is a non sequitur. The number of neurons in the cetacean brain is, in fact, quite high. Neuron number and neuronal density are two completely different and often independent values. What is low in the cetacean neocortex, as in all big-brained mammals, is the neuronal density. Confusing density and number can, and often does, lead to the erroneous conclusions that Manger (2006) draws, which are precisely the type of errors that can be avoided using unbiased stereological methods and approaches.

\section{(4) Columnar, modular and clustering organization}

Manger (2006, p. 305) states that: "it is difficult to identify columnar and microcolumnar organisation in the photomicrographs of architectonically defined regions of dolphin brain. . .whereas these features are readily identifiable in the cortex of other mammals". This is incorrect. Several lines of 
evidence exist in support of columnar, modular and clustering organisation in the cetacean neocortex. Hof \& Van der Gucht (2007) reported a remarkable layer II clustering pattern in the anterior insular cortex in mysticetes. This had been reported earlier in the bottlenose dolphin (Manger et al., 1998). Moreover, layer II clustering occurs in a large region of the occipital cortex of the humpback whale and the fin whale as well. These observations represent strong evidence for organisational complexity and specialisation of the cetacean neocortex and point to the evolution of different regional specialisations in odontocetes and mysticetes. This peculiar distribution of layer II clustering may represent a strategy to optimize the connectivity of intrahemispheric pathways in the very large brains of mysticetes. This theory is further supported by the observation that layer II clustering neurons often align with groups of small pyramidal neurons in the underlying layer V (Hof \& Van der Gucht, 2007).

Furthermore, Morgane et al. (1988) reported the presence of vertical major and minor columns of neurons in the visual cortex of the striped dolphin. Similar findings were made in the visual and auditory cortices of the humpback whale and several other cetacean species (Hof \& Van der Gucht, 2007). Although Manger (2006, p. 306) reported the Morgane et al. (1988) findings on the size of the major and the minor columns in the striped dolphin visual cortex as being smaller than the columns or modules observed in primates and humans, he completely omitted the striking observation of Morgane et al. (1988) that major and minor cytoarchitectonic columns in human and striped dolphin visual cortex contain practically the same number of synapses.

The biological significance of columns, modules and clusters is likely to be related to a need for optimisation of wiring among cortical domains and to limit the energy demands generated by such circuits. This idea is consistent with the finding of Hof \& Van der Gucht (2007) that largebrained mysticetes have a more extensive modular organisation of layer II than smaller-brained odontocetes. Finally, the differing patterns of columns, modules and clustering observed in odontocetes and mysticetes might be seen as a specific evolutionary route to organising networks in possibly highly specialised cortical regions (Hof \& Van der Gucht, 2007; Jacobs et al., 1984).

\section{(5) Cell typology and neurochemistry}

General homogeneity in neuronal typology in the cetacean neocortex has been described several times (Glezer \& Morgane, 1990; Morgane et al., 1988) and is reiterated at the chemoarchitectonic level showing the distribution pattern of calcium-binding proteins, with a predominance of calbindin- and calretinin-containing neurons in the upper layers and a paucity of parvalbumin-immunoreactive neurons (Hof et al., 1999; Hof \& Sherwood, 2005). Manger (2006, p. 307) concludes: "...the relative paucity of parvalbumin-immunoreactive cells indicates a lack of horizontal inhibitory influences, potentially characterizing inefficient horizontal processing between cortical columns, and suggesting poor integrative abilities". However, it is likely that the integration of the column's activity in the cetacean cortex occurs in the thick layer I within which $70 \%$ of the total cortical synapses in odontocetes are contained (Glezer \& Morgane, 1990) and where the majority of calbindin- and calretinin-expressing inhibitory interneurons are located (Hof et al., 1999). Moreover, the fact that the usual parvalbumin-containing neurons are not visible in cetaceans does not mean that these do not exist they may simply not be expressed in the same way as in other mammals. Major differences in calcium-binding protein expression have indeed been reported in many neuronal types across a large range of mammals (Hof et al., 1999). Thus, here again, Manger's (2006) conclusion is based upon unreliable assumptions.

Furthermore, Manger (2006, p. 332) claims that: "It is demonstrated that there are no neurological correlates for the purported intellectual abilities of cetaceans..." and again "The neuroanatomical features of the cetacean cerebral hemisphere do not indicate a structure supportive of high levels of intellectual capacities." The cetacean species with the largest brains (and also the largest bodies) exhibit a large number of spindle-shaped Von Economo neurons in layer $\mathrm{V}$ of the anterior cingulate, the frontoinsular and the frontopolar cortices (Hof \& Van der Gucht, 2007). Von Economo neurons are highly specialised projection neurons considered to be involved in neural networks subserving aspects of social cognition (Allman et al., 2005). The presence of these neurons in cetaceans does not demonstrate, but is consistent with, complex cognitive abilities in this group. Prior to their identification in two mysticete species, the humpback whale and the fin whale, and in two odontocetes species, the sperm whale (Physeter macrocephalus) and the killer whale, Von Economo neurons were thought to be a neuronal type unique to humans and great apes (Nimchinsky et al., 1995, 1999). Given the 95 million years that separate the evolutionary history of cetaceans and primates (Kumar \& Blair Hedges, 1998) it is likely that Von Economo neurons evolved independently in these taxa as a consequence of separate, yet potentially similar, selective pressures. Moreover, as proposed by Hof \& Van der Gucht (2007), if Von Economo neurons arose in the ancestor of the extant taxa that possess this unusual neuronal morphotype, we speculate that these highly specialised cells evolved in cetaceans several millions years earlier than in primates.

The regional and laminar distribution of Von Economo neurons is similar for both cetaceans and hominids. However, these neurons have also been observed in cetaceans with a scattered distribution in areas where they have not been found in hominids such as the frontopolar cortex, inferior temporal cortex, inferior surface of the occipital region and posterior part of the cingulate and retrosplenial cortices (Hof \& Van der Gucht, 2007). Concentrations of Von Economo neurons in selected areas of the brain classically involved in high-level cognitive functions in primates (the anterior cingulate, frontoinsular and frontopolar cortices) are a strong indication of the anatomical and functional specialization of these cortical areas in cetaceans. The highly localised presence of Von Economo neurons in species with the largest brains both 
among primates and cetaceans leads to speculations about the possible role of these cells in the reorganisation of cognition-related specific functional connectivity pathways as a consequence of brain size increase. This might explain the relative rarity of Von Economo neurons in odontocetes with a smaller absolute brain size (Hof \& Van der Gucht, 2007). In particular, the long and wide axons of these cells have been related to a possible role in fast relay of outputs from and possibly between the anterior cingulate and frontoinsular cortices (Allman, Hakeem \& Watson, 2002; Allman et al., 2005). Hominids and cetaceans, groups with the biggest absolute brain sizes, seem to be "equipped" to compensate for longer distances of information processing, thus maintaining an efficient and fast transmission among specialised areas of the brain. Although this cell type is not a unique feature of cetaceans, it should be noted that cetaceans are among the very few non-primate species in which spindle cells have been identified to date. The evolution of this particular cell type in two distantly related taxa that show comparable levels of behavioural complexity, suggests that spindle cells might be the neurological result of selective pressure acting on complex cognitive processes.

\section{(6) Hippocampal formation}

All the subregions of the hippocampal formation typical of terrestrial mammals (dentate gyrus, hippocampus proper and subiculum, plus the entorhinal cortex) are found in cetaceans (Breathnach \& Goldby, 1954; Hof et al., 2005; Hof \& Van der Gucht, 2007). However, as Manger (2006) points out, this formation is relatively small in cetaceans compared to the hippocampal size in large-brained terrestrial mammals like the elephant (Loxodonta africana) (Hakeem et al., 2005). Hakeem et al. (2005) found that the two closest relatives of the elephant, the terrestrial rock hyrax (Procavia capensis) and the aquatic "Florida" manatee (Trichechus manatus latirostris) have a large and a very small hippocampus, respectively. This paradoxical finding inevitably led to the speculation that the development of the hippocampus, recently suggested to be independently regulated with respect to other brain structures, followed a different evolutionary pathway in aquatic mammals compared to terrestrial mammals. Furthermore, the relatively small size of the hippocampus in both odontocetes and mysticetes is strikingly offset by the well-differentiated and extended entorhinal cortex (Breathnach \& Golby, 1954; Hof \& Van der Gucht, 2007). Particularly, the diminutive dentate gyrus, the major projection area of the entorhinal cortex (Zola-Morgan \& Squire, 1993), suggests that the cetacean memory storage system might use strategies that involve a different circuitry and additional regions as well as the hippocampus (Marino et al., 2004b; Oelschlager \& Oelschlager, 2002). In this context, the general observations Manger (2006, p. 311) reported about the size of the hippocampal formation are limited to merely a gross analysis that ignores the relevant extensive and differentiated entorhinal cortex.

In conclusion, the current evidence suggests that cetacean cortical organisation is complex but very different from, and certainly not inferior to, that found in other mammals. Compared to terrestrial mammals, most cetaceans have clearly elaborated parietal and temporal regions, the purposes of which remain largely unknown. Cetaceans possess a large domain of frontal cortex that is the likely homologue of the primate prefrontal cortex, however, it is also likely that the functional analogue of primate prefrontal cortex spreads onto other neocortical territories (e.g. the highly expanded temporal and parietal regions). Cetaceans also possess unique cytoarchitectural features related to columnarity and modularity that are likely related to specialised wiring of specific cortical fields. They share with hominids a unique type of neuron in the same location of the anterior cingulate cortex and insular cortices, but cetaceans may have been first to evolve these neurons. Furthermore, cytoarchitecture, even for primary cortical fields, is quite variable among cetaceans, and certainly between odontocetes and mysticetes. We consider such differences strong neurobiological support for complex cognitive and behavioural abilities in cetaceans.

\section{CLAIM 3: THERE IS NO BEHAVIOURAL EVIDENGE FOR GOMPLEX GOGNITION IN GETAGEANS}

Manger (2006) makes the sweeping claim that there is no behavioural evidence for complex cognition in cetaceans. In doing so he refers to several specific domains of evidence: (1) learning and memory, (2) vocalisations and communication, and (3) cognitive and social convergence with other mammals, particularly humans and other primates. However, there are two glaring limitations to Manger's (2006) discussion of dolphin cognition: (i) his often erroneous conclusions about the data he presents and (ii) his omission of a large literature demonstrating sophisticated cognitive skills in dolphins. Here, we review the cognitive issues discussed by Manger (2006) and show why his interpretations are inadequate and misinformed. In addition, we summarise a large number of published studies not considered by Manger (2006) that reveal impressive intellectual accomplishment by dolphins and illustrate the high degree of behavioural complexity and flexibility in these animals. Our review is mainly focused on the bottlenose dolphin, the most well-studied species on cognitive capabilities, unless otherwise indicated.

\section{(1) Memory and learning}

Manger (2006, p. 320) argues from analogy with foodcaching versus non-food-caching birds that the relatively small hippocampal formation in cetaceans implies poor spatial memory and, in general, "suggest(s) that functions related to hippocampal processing must be compromised in cetaceans". The hippocampus is involved in long- and short-term memory processing and these processes form the foundation for learning capacities. Consequently, Manger (2006) is advancing a strong claim that amounts to implying that cetaceans not only possess poor memory but are poor learners as well. In making this claim, he ignores, or is 
unaware of, a large body of data showing otherwise. Various dimensions of intellectual performance in cetaceans (again, mainly but not exclusively, bottlenose dolphins) have been investigated in laboratory studies, including declarative and procedural knowledge (knowing what things or events are, and knowing how to manipulate those elements), social knowledge, and self knowledge (reviewed in Herman, 2006). All these varieties of intellectual performance rest on a strong foundation of memory. Moreover, direct studies of dolphin short-term or "working" memory - processing of new information and retaining it in conscious memory have shown that auditory memory (memory for things heard), visual memory (memory for things seen, including objects and behaviours), and spatial memory (memory for locations) are well developed and robust (Herman, 1975; Herman \& Gordon, 1974; Herman \& Thompson, 1982; Herman et al., 1989; Reiss \& McCowan, 1993; Richards, Wolz \& Herman, 1984; Thompson \& Herman, 1977, 1981). Where comparisons are available, dolphin short-term memory is similar in its fidelity and its characteristics to the demonstrated short-term memory capabilities of nonhuman primates (e.g. D'Amato, 1973), or in the case of probe memory - memory for lists of items - comparable to memory characteristics demonstrated in humans (Herman, 1980; Thompson \& Herman, 1977). In two studies cited above, for example, a dolphin listened to lists of as many as eight different short sounds and then indicated whether a probe sound occurring after the list was presented was or was not a member of that list (Herman, 1980; Thompson \& Herman, 1977). The dolphin could retain up to five items in memory reliably. As in human studies of list memory, the dolphin's memory was better for later items in the list than for earlier items (the so-called "recency effect") (see, e.g., Waugh \& Norman, 1965).

Although there are no formal studies of long-term memory in dolphins (which may include reference memory, procedural memory, declarative memory and more), the dolphins in Herman, Richards \& Wolz (1984) remembered vocabulary items and syntactic rules over months without practice (declarative and reference memory). With respect to spatial memory, Manger (2006) overlooks the work of Xitco, Cory \& Kuczaj (2001) that showed, in part, the dolphin's ability to remember the spatial locations of named structures in an extensive habitat. Likewise, field studies (e.g. Connor, 2007) reveal the importance of learning and remembering the individuals of one's community, their characteristics and interrelationships, and their relationships to oneself - all abilities reliant upon strong long-term memory.

There is a large body of data demonstrating sophisticated cognitive abilities by dolphins that was not discussed or considered by Manger (2006). These various studies illustrate impressive learning capacities and behavioural flexibility in dolphins. Flexibility in behaviour - "the ability to modify behaviour adaptively in the face of new evidence or changes in world conditions (Herman, 2006, p. 441)" is probably one of the strongest indicants of a high level of intellectual functioning. Some of the findings ignored by Manger (2006) include:

(a) Dolphins demonstrate the ability to learn a variety of types of governing rules for solving abstract problems
(Herman, Pack \& Wood, 1994). For example, they can reliably classify pairs of objects as "same" or "different" (Herman \& Gordon, 1974; Mercado et al., 2000).

(b) Dolphins understand representations of the real world. They have demonstrated a spontaneous (untrained) ability to respond to instructions from the small images of televised trainers with the same fidelity that these responses are made to "live" trainers (Herman, Morrel-Samuels \& Pack, 1990);

(c) Dolphins learn and master not only the semantic features of artificial gestural and acoustic languages, but also the syntactic features (Herman et al., 1984; Herman, Kuczaj \& Holder, 1993a) (see below). After a certain level of proficiency was attained with elementary syntactic structures, learning of more complex syntactic structures was accomplished by dolphins through inference, rather than through explicit instruction

(d) Dolphins are one of the few species that can imitate both arbitrary sounds and arbitrary behaviours (Richards et al., 1984; Reiss \& McCowan, 1993; Herman, 2002). For example, they can imitate electronically generated sounds of a variety of waveforms and they can mimic the motor behaviours of another dolphin or a human demonstrator, viewed either live or via television images. Moreover, dolphins have demonstrated an understanding of the abstract concept of "imitate" (Herman, 2002; Xitco, 1988).

(e) Dolphins can learn numerical concepts. After learning to select a set of two items out of a set of five, a dolphin demonstrated successfully that it had learned a concept of numerically "less" by generalising to novel sets outside of the numerical ranges used in training (Jaakkola et al., 2005; Kilian et al., 2003).

(f) Dolphins can innovate motor behaviours in paradigms requesting innovation and pairs of dolphins can "create" the same behaviour in close synchrony (Braslau-Schneck, 1994; Herman, 2006; Pryor, Haag \& O'Reilly, 1969).

(g) Complexly shaped objects perceived through echolocation alone can be spontaneously recognised through vision alone, and vice-versa (Herman, Pack \& HoffmannKuhnt, 1998; Pack \& Herman, 1995). Like visual perception, echolocation perception for the dolphin appears to represent the whole object rather than only selected features (Pack et al., 2002). Moreover, the ability to transfer across sensory modalities (cross-modal transfer) has been linked to a variety of intellectual functions in humans and non-human primates (e.g. Rose \& Wallace, 1985; Gunderson, Rose \& GrantWebster, 1990).

(h) Dolphins can reliably choose the object pointed to by a human informant or gazed at with a turn of the head (Pack \& Herman, 2004, 2006, 2007; Tschudin et al., 2001). Dolphins can also understand spontaneously the use of pointing gestures substituted for symbolic gestures in language-like tasks (Herman et al., 1999). Additionally, dolphins can spontaneously produce pointing (using rostrum and body alignment) to 
communicate desired objects to a human observer (Xitco et al., 2001), and appear to understand that the human observer must be present and attending to the pointing dolphin for communication to be effective (Xitco, Gory \& Kuczaj, 2004).

( $\imath$ Dolphins appear to have a sense of what they know and what they don't know-often termed metacognition. Smith et al. (1995) demonstrated that a dolphin will use an "escape" response when he/she is uncertain about the classification of a sound it is listening to. The dolphin presses one paddle if a sound is perceptibly high in pitch and another paddle if low, or a third paddle if it is uncertain.

(j) Dolphins have demonstrated rapid and spontaneous vocal imitation, vocal learning, and the ability to develop learned associations between temporally paired elements in the absence of explicit training (Hooper et al., 2006; Reiss \& McCowan, 1993).

\section{(2) Vocalisations and communication}

(a) Vocal behaviour, vocal learning and cultural transmission

Manger (2006) makes two major errors in his treatment of cetacean vocal behaviour. The first is the claim that 'investigators still persist with the possibility that dolphins have a language' (p. 312). He erects this straw man by referring to the early hypothesis of Lilly (1967) that dolphins possess a language as sophisticated as that of humans. In doing so Manger (2006) ignores the fact that most contemporary scientists investigating cetacean communication do not accept Lilly's (1967) original hypothesis of a human-like language in cetaceans and have not for many years (see e.g., Caldwell \& Caldwell, 1966; Herman \& Tavolga, 1980; Wilson, 1975; Wood, 1973). The two books by Lilly that Manger (2006) cites have, according to the ISI Citation Index, themselves been cited only once since 1972 in papers about cetacean vocal behaviour - hardly an active endorsement. While scientists today have largely dismissed claims for human-equivalent language in cetaceans, it is widely recognised that cetacean communication is varied and complex in its own right.

Manger (2006) argues that cetacean vocalisations and conspecific communication are involuntary, stereotyped, simplistic and limited. Specifically, he asserts that "vocalisations of the dolphin must be mainly under control of a mesencephalic structure, with minor telencephalic influence. This feature of the cetacean brain indicates a specialised, but probably non-conscious and involuntary, vocal generation system..." (p. 313; see also similar arguments advanced on p. 318). This is the basis for Manger's second major error in his treatment: the claim that the dolphin vocal repertoire is limited to "seven different species-specific calls...'(p. 298) - less than that observed in many other mammals. Manger's (2006) claim that dolphins possess an unsophisticated communication system is contradicted by an abundant literature on cetacean vocal behaviour and vocal learning (e.g. Deecke, Ford \& Spong, 2000; Ford 1991; Janik, 1999; Janik \& Slater, 1997; Janik et al., 2006; McCowan \& Reiss, 1995 a,b; Miller \& Bain, 2000; Noad et al., 2000; Reiss \& McCowan, 1993; Rendell \& Whitehead, 2003; Richards, 1986; Sayigh et al., 1990, 1999; Smolker, Mann \& Smuts, 1993; Stafford, Nieukirk \& Fox, 2001; Tyack, 1986; Tyack \& Sayigh, 1997; Yurk et al., 2002;). This literature pertains in particular to the four best-studied species - the bottlenose dolphin, killer whale, humpback whale and sperm whale.

Bottlenose dolphins are adept vocal learners, a trait rare among mammals (Caldwell, Caldwell \& Tyack, 1990; Deecke et al., 2000; Hooper et al., 2006; Janik \& Slater, 1997; McCowan \& Reiss, 1995b; Reiss \& McCowan, 1993; Richards et al., 1984). In fact, a large proportion of vocal variation within cetacean species is likely the result of vocal learning (Rendell \& Whitehead, 2001). There is evidence for individual-level variation in the whistle repertoires of dolphins (McCowan \& Reiss, 2005a). Bottlenose dolphins produce individually distinctive whistles that they apparently use to identify conspecifics and may also be employed as a cohesion call (Janik \& Slater, 1998; McCowan \& Reiss, $1995 a, 2001)$. There are different viewpoints as to whether these whistles are actually different whistle types, known as "signature whistles" (Sayigh et al., 1999; Janik et al., 2006; Tyack, 1997) or a shared rise-type whistle that is individually distinctive, similar to the contact calls of many other species (McCowan \& Reiss, 1995a, 2001). In either case there is little disagreement that these are individually distinctive calls that predominate within a much larger whistle repertoire (Janik \& Slater, 1998; McCowan \& Reiss, 1995a). Manger (2006) refers to these whistles to suggest that dolphins may simply be learning that "increasing pod coherence in response to a specific vocalisation decreases their chance of being predated" (p. 318). This suggestion demonstrates a lack of understanding of whistle variation in dolphins. There is population-level variation in whistle parameters (Ding, Wursig \& Evans, 1995) and two cases of population-specific (i.e. again - not species typical) nonwhistle call types - 'bray' calls associated with salmon capture off eastern Scotland (Janik, 2000) and 'pop' calls associated with male aggression in Shark Bay, western Australia (Connor \& Smolker, 1996). The claim that dolphin calls are 'species-specific' is wrong; there is abundant withinspecies variation in dolphin vocal output.

Other research that has explored dolphin vocal repertoires and complexity of dolphin communication (McCowan \& Reiss, 1995a; McCowan, Hanser \& Doyle, 1999, 2002) has shown that dolphins produce many different whistle types and that there is some evidence that the sequential order of whistles is an important feature of their whistled communication. Manger's (2006) claim that "[McCowan et al.'s] results suggested a certain level of internal structure to be present in dolphin vocalisations; however, it was clear that higher order entropies, typical of human language, were not found" (p. 312) is misleading. Internal structure (secondorder entropy) was indeed present. Furthermore, McCowan et al. $(1999,2002)$ limited their analysis to second-order entropies due to sample size; therefore, they have not yet explored whether dolphin whistled communication exhibits higher orders of entropy indicative of more complex communication. Indeed, data from McCowan et al. (1999, 2002) suggest that at least for two-whistle sequences (second-order 
entropy) internal structure is present. Future research on a larger corpus of data will be needed to explore whether the dolphin communication system continues to exhibit evidence of internal structure and thus complexity at higher levels.

Similarly, the vocal repertoires of killer whales could not possibly be described as 'species specific'. These animals produce dozens of community, clan and pod-specific call types (Ford, 1991; Yurk et al., 2002), and there is documentation that call types evolve over time and in parallel when shared between separate but associating pods (Deecke et al., 2000). In fact, within-species variation in killer whale calls is so pronounced that other marine mammals have learned to tell them apart based on their calls - harbor seals become selectively habituated to the calls of local fish-eating pods but not to local mammaleating pods nor to strange fish-eating pods (Deecke, Slater \& Ford, 2002). Such phenomena would be impossible were killer whale calls 'species specific', as Manger(2006) suggests.

Manger (2006) makes the claim that dolphin vocalisations are involuntary unconscious acts controlled by the brainstem. However the literature on dolphin vocal learning and behaviour clearly contradicts this view. As previously noted, dolphins have demonstrated superb vocal control in several published studies. Dolphins are, in fact, excellent vocal mimics capable at either their own discretion or "on command" of imitating a wide variety of arbitrary electronic sounds broadcast into their habitat (Reiss \& McCowan, 1993; Richards et al., 1984). They have also shown analogous stages in vocal development to those reported for humans and songbirds, including imitation, overproduction and vocal play (Hooper et al., 2006; Reiss \& McCowan, 1993; McCowan \& Reiss, 1995b) In one study, a group of dolphins was provided with an underwater keyboard that gave them choice and control over specific keys that were associated with specific contingencies specific synthesised whistles were generated that were immediately followed with specific objects and activities delivered to the dolphins (Reiss \& McCowan, 1993). The dolphins actively used the keyboard and demonstrated rapid and spontaneous vocal imitation of the novel whistles, produced facsimiles of the novel whistles in behaviourally appropriate contexts and showed evidence for learned associations between the visual keyboard and the temporally paired acoustic signals and objects and activities. These results also indicated the dolphins formed learned associations between temporally related events in their environment without explicit training and demonstrated active and contextually appropriate use of newly learned signals in behaviourally flexible ways within a changing environment.

In another example, Richards et al. (1984) demonstrated a dolphin's ability to copy pure tones, sine waves, square waves, triangle waves, and pulse-like sounds. Further, the dolphin subject was able to reproduce the contour of the model sound an octave below or above the model, when the model was out of the dolphin's preferred vocal range. These skills obviously require exquisite vocal control and flexibility. Dolphins are also able to control the spectral content, amplitude, and click rate of their echolocation sounds (Au, 1993). All of the above studies provide an empirical contradiction to Manger's(2006) claim that the vocalisations of dolphins are involuntary rudimentary unconscious sounds.

Manger (2006) criticizes reports of cultural transmission in humpback whale song by suggesting that a similar behaviour to 'birds copying each other's songs but with a low and constant random error rate' (p. 319) could explain the patterns observed. This criticism is confused on a number of levels. First, the fact that birds may exhibit some similar behavioural characteristics to cetaceans and other mammals does not imply that the mammalian behaviour is simple; rather, use of this comparison reveals a misguided and rather outdated assumption about the simplicity of avian behaviour (Emery, 2006). Notwithstanding the fact that the song-copying he describes in birds is routinely described as cultural transmission by ornithologists (e.g. Slater, 1986), his criticism is mistaken. Copying (or some other form of social learning) with error is a large part of the nature of culture (e.g. Boyd \& Richerson, 1985), but not all. The other attribute generally ascribed to culture is that it is collective or convergent (e.g. McGrew, 2003). A constant random error rate would clearly result in the opposite of convergence - increasing song divergence over time. This is not the case in humpbacks where some mechanism acts to restrict severely this divergence such that all members of a population sing the same song. Neither can a constant random error rate explain Noad et al.'s (2000) observation of a cultural revolution wherein an entire humpback whale population rapidly altered its song to that used by another population over a period that would ordinarily see just a few phrases being modified.

In addition, recent work on sperm whales has documented over 33 types of 'coda' vocalisations (rhythmic patterns of clicks) and shown how their use varies among social groups (Rendell \& Whitehead, 2003). In one study, a single social unit of sperm whales comprising nine animals was shown to produce around 30 different coda types. Again, the claim that calls are "species-specific" does not hold. The only known parallel to the sympatry of social groups with distinct cultures in killer and sperm whales is in the multicultural societies of humans (although elephants may possess this attribute) (Rendell \& Whitehead, 2001). Multifaceted cultures such as those found in these two species (killer whales have cultural attributes in vocal, social, feeding and play behaviour) have known parallels only among the great apes and other cognitively complex primates such as capuchins (although, once again, elephants may also share this attribute). Thus, to reiterate, the fact that birds may exhibit some similar characteristics to cetaceans and other mammals does not imply that the mammalian behaviour is simple. Rather, Manger's (2006) use of the comparison reveals a misguided and outdated assumption about the simplicity of avian behaviour.

\section{(b) Cetacean non-vocal behaviour}

Manger (2006) extends his argument about limited communication in cetaceans to the non-vocal domain. 
Citing loss of facial expression, a streamlined body, and loss of limbs, he states: "This body language repertoire is clearly limited to gross movements" (p. 312). First, "gross" is a relative term; the avoidance of eye contact by some primates may be viewed by some as gross and others as subtle. Second, the limitation to so-called gross body movements does not mean that these movements are not communicative or that they cannot communicate subtle messages. Again, Manger (2006) demonstrates a primatecentered and woefully parochial view of the diversity of expression and movement available to cetaceans. Manger disregards the rich body of in situ and ex situ research that describes an extensive diversity of non-vocal behaviour used by cetaceans in affiliative, epimeletic (care-giving), and disciplinary contexts (Caldwell \& Caldwell, 1965, 1966; Connor \& Norris, 1982; Tavolga \& Essapian, 1957), showing that dolphins can convey not only intention but motivation using non-vocal behaviours (reviewed in Lusseau, 2006; Tyack, 2000). For example, bottlenose dolphins display aggression by vigorous, jerky movements of their head, often up and down, and by opening the mouth, baring teeth. A U-shaped posture sometimes precedes an aggressive strike by the tail. Fear or apprehension may be displayed by the bulging of the eyes, revealing the sclera. By contrast, closing of the eyes with little muscle tension is often associated with a more relaxed state. Submissive movements may include flinching and orienting the body away from the aggressor. Sexual communication may include display of the ventral region and an S-shaped posture (e.g. see Madsen \& Herman, 1980; Puente \& Dewsbury, 1976).

Non-vocal behaviours are also used to synchronise the activity of dolphin schools (Lusseau, 2007). Additionally, cetaceans in general often supplement their rich vocal repertoire with visual cues (e.g. changes in body posture), tactile behaviours (e.g. flipper touching), and non-vocal acoustic behaviours (e.g., lobtailing) (see Herzing, 2000, for a review; also Dudzinski, Thomas \& Douaze, 2000). Furthermore, recent analyses show that the performance of behavioural events is structured in time with long-range correlation in the temporal sequence of behavioural events which is only paralleled by human language (Ferrer i Cancho \& Lusseau, 2006). As another example, male humpback whales in the winter reproductive grounds, when engaged in aggressive male-male competition, often inflate their ventral pleats, enlarging their apparent size (Baker \& Herman, 1984) and sometimes perform S-shaped postures (Helweg, Bauer \& Herman, 1992).

\section{(c) Artificial language comprehension}

Regardless of the evidence for a human-like natural language in cetaceans, a significant empirical question about language is whether dolphins can learn to understand a symbolic language-like system comprised of both semantic and syntactic features, the two key components of any human natural language (Pavio \& Begg, 1981). Manger (2006) misunderstands the essence of the language work with dolphins when he states, "At best, dolphins have been shown to be capable of learning approximately 40 symbolic associations (or 'words')" (p. 294). Human language gains its versatility and communicative power not through the word, but through the sentence. Even with a limited vocabulary of words, a large number of unique sentences may be created by combining words in various ways and in various sentence lengths according to syntactic rules. In human language, there are an infinite number of possibilities. In the dolphin language comprehension study of Herman et al. (1984) (see also Herman, 1986, 1987; Herman et al., 1993a; Herman, Pack \& Morrel-Samuels, 1993b), using several different syntactic rules, thousands of unique sentences could be constructed from the finite 40-item vocabulary and acted on appropriately by the dolphins. Among nonhumans, only the great apes, particularly the bonobo (Pan paniscus), have shown this type of ability (e.g. Savage-Rumbaugh et al., 1993).

The symbolic language-like system learned by the dolphins conveyed instructions, many of which were novel, to carry out named actions to named objects or required the dolphins to construct relationships between pairs of objects, such as placing one named object next to or on top of another named object. Symbols could be expressed either as electronically generated sounds broadcast underwater, or as gestures of a trainer's arms and hands. In their responses, the dolphins took account of both the semantic component (the referents of the symbols, i.e. the object, action, or relationship that the symbol represented) and the syntactic component Thow symbol ("word") order affected the meaning of the instruction]. There was roughly comparable understanding whether the symbols were presented via the acoustic or the visual system across hundreds of novel sentences.

One of the hallmarks of symbol processing is an understanding that symbols can refer-that they can represent or stand for objects, actions, or events. One of the strongest indications of this is an understanding of the referent of the symbol even when the referent is absent. Work by Herman \& Forestell (1985) showed that a bottlenose dolphin could respond reliably and accurately to questions asking whether a named object indicated by a gestural symbol was present or not in the dolphin's habitat. The dolphin could respond "present" or "absent" by pressing the appropriate paddle to her right ("present") or left ("absent"). Her responses were $80 \%$ correct or better, providing strong evidence that she understood that the symbol stood for or referenced a particular object, even if that object was absent from her surroundings.

\section{(3) Cognitive and social convergence with non-human primates}

Manger (2006) challenges the claim by Marino (2002) that cetaceans and primates possess some convergent cognitive abilities (in social behaviour, artificial language comprehension, and self-recognition, for instance) that may be related to their large brains (or high EQs). He critiques the idea of convergence in social complexity by appealing to the fact that many socially complex behaviours (e.g. alloparenting) are found across a range of EQ levels in cetaceans. He notes, for example, that both sperm whales $(\mathrm{EQ}=0.44)$, and bottlenose dolphins $(\mathrm{EQ}=4.2$ ), exhibit alloparenting behaviour and thus concludes that there is no relationship 
between complex social behaviours and brain size. The claims made by Marino (2002) are, therefore, unfounded, he argues. But Manger (2006) neglects to take into account the fact that the effectiveness of EQ comparisons at the ends of the range of body sizes, as in the sperm whales, breaks down because of nonlinearity. More importantly, Manger (2006) has completely missed the main point of Marino (2002), which is that some highly complex social behaviours might be found in both primates and cetaceans because both groups contain species with large, complex brains.

Manger (2006) contends that several socially complex behaviours cited in Marino (2002), such as cultural transmission and alliance formation, have not been sufficiently documented to allow independent scrutiny. Here again, he ignores a substantial body of evidence for social complexity and culture in cetaceans. The hypothesized relationship between social complexity and brain size is that social complexity was a driving force in the evolution of intellect, and by implication, in the expansion of the brain, as first hypothesised for dolphins by Herman (1980) and for animals in general by Humphrey (1976). What we have learned from two well-studied dolphin societies (bottlenose dolphins and killer whales) suggests that dolphins live in large highly complex societies with differentiated relationships (Baird, 2000; Connor et al., 2000; Lusseau, 2007) that include long-term bonds, higher order alliances and cooperative networks (Baird, 2000; Connor et al., 2000) that rely upon learning and memory. Some of the complexities typical of within-group primate alliances, such as individuals switching sides in different social contexts, are also seen among bottlenose dolphins. The most complex nonhuman social relationships described to date are among bottlenose dolphins in Shark Bay, Western Australia. Males in this population form two and possibly three levels of nested alliances within a social network numbering in the hundreds. Males cooperate in groups of 2-3 to form consortships, often initiated and maintained with aggression, with individual estrus females (Connor et al., 1992a, b, 1996). Males also hold membership in larger groups of 4-14 individuals that cooperate in competition with other groups over oestrus females. The alliance bonds between males, both within the pairs and trios, and among males in the larger groups, are maintained by affiliative behaviour such as petting and possibly even synchrony (Connor, 2007). Similar complex relationships are present in another bottlenose dolphin population in Doubtful Sound, New Zealand in which males form groups and higher order relationships, interacting in several social dimensions (Lusseau, 2007). Males also use petting to maintain group-level affiliations, and fights between groups are observed. However, male relationships in this population further indicate the potential for forward planning in bottlenose dolphins since competition between male groups does not lead to the immediate benefits of female consortship observed in Shark Bay but to a longer term benefit of female access (Lusseau, 2007). Some of the complexities typical of within-group primate alliances, such as individuals switching sides in different social contexts, are also seen among the Shark Bay and Doubtful Sound males (Connor et al., 1992a; Lusseau, 2007) Such 'alliances of alliances' are rare outside of our own species, even among old world monkeys and apes (Connor et al., 1992b). There is also evidence that individual role-taking has emerged in dolphin societies to facilitate cooperative relationships (Gazda et al., 2005) and decision-making processes (Lusseau, 2006, 2007).

Field studies have documented impressive cultural learning of dialects, foraging sites, and feeding strategies in cetaceans. Culture, the transmission of learned behaviour, is one of the attributes of cetaceans that most sets them apart from the majority of other nonhuman species (Rendell \& Whitehead, 2001) and is likely underpinned by advanced social learning abilities such as imitation (Herman, 2002; Herman \& Pack, 2001). Cultural attributes have been identified in many species of cetaceans but principally in those best-studied: the bottlenose dolphin, the killer whale, the sperm whale, and the humpback whale (Rendell \& Whitehead, 2001). Tool use has been documented among bottlenose dolphins, who use sponges to probe into crevices for prey and appear to transmit the technique culturally (Krûtzen et al., 2005).

One of the most distinctive elements of cetacean culture is multiculturalism (groups with different cultures using the same habitat) which is known in bottlenose dolphins, humpback whales, killer whales and sperm whales. For example, killer whale populations of the eastern North Pacific are structured into several social tiers, which possess distinctive cultural attributes in vocal, social, feeding and play behaviour (Ford, Ellis \& Balcomb, 2000; Yurk, 2003).

A recent study of sperm whales found strong indications of fitness differences between sympatric cultural clans of sperm whales (Marcoux, Rendell \& Whitehead, 2007). There is very little other evidence that cultural differences affect fitness, except in humans. If culture affects fitness, then gene-culture coevolution - a phenomenon often believed to be unique to humans - is likely (Feldman \& Laland, 1996). However, there are several strong suggestions of culture affecting genetic evolution in cetaceans, including the divergence of the types of killer whales, and the low mitochondrial diversity of matrilineal groups being caused by the phenomenon of cultural hitchhiking (Rendell \& Whitehead, 2001).

Manger (2006) criticises the notion that comprehension of an artificial language is a convergent ability across cetaceans (specifically bottlenose dolphins) and primates (specifically great apes), as suggested by Marino (2002). The point of identifying language comprehension as a convergent trait in great apes and cetaceans in Marino (2002) was to show that very few species can even be meaningfully engaged in studies of comprehension of a symbolic, rulebased, artificial language and that comprehension of these languages by great apes and dolphins is a further illustration of the convergence of these species in cognitive skills.

Finally, Manger (2006) suggests that while the evidence for mirror self-recognition (MSR) in chimpanzees is robust, the findings of Reiss \& Marino (2001) showing MSR in bottlenose dolphins are questionable. This contention is based on a serious misunderstanding and misrepresentation of the Reiss and Marino (2001) study. Manger (2006) points to weaknesses in other studies of MSR in cetaceans (e.g., Delfour \& Marten, 2001) to make the argument that 
Reiss \& Marino (2001) is, by extension, equally flawed. Previous studies that investigated this ability in cetaceans did not employ sufficient controls nor did they claim to convincingly demonstrate MSR (Delfour \& Marten, 2001; Marino et al., 1994; Marten \& Psarakos, 1994). By contrast, Reiss \& Marino (2001) demonstrated MSR unequivocably in a rigorous study with proper experimental controls.

Manger (2006) claims that Reiss \& Marino (2001) relied solely on latency (time between marking, sham marking or no marking event to the dolphin's arrival time at the mirror) measures to infer cognitive activity. This is incorrect. Latency data was but one of multiple lines of evidence in support of the conclusion that the dolphins demonstrated MSR. Reiss \& Marino (2001) tested their main hypothesis by quantifying identifiable behaviours that allowed them to distinguish between cognitive stages in their subjects. These behaviours were categorised as self-directed, exploratory, non-directed, social, or ambiguous (see Table 1 in Reiss \& Marino, 2001). Latency was employed as an additional measure to impose further rigour on the testing of multiple hypotheses about whether the dolphins recognised themselves in mirrors. Importantly, the conclusion that the dolphins demonstrated MSR was based on several measures and multiple tests that employed rigorous controls.

Manger (2006) also criticises Reiss \& Marino (2001) by claiming that unmarked dolphins spent almost as much time at the mirror as marked individuals and the target behaviour was increased in the absence of a mirror. This is also incorrect. Reiss \& Marino (2001 found that the time spent at the mirror when marked was significantly greater than under any other condition - precisely what would be predicted by the self-recognition hypothesis. Figure $3 \mathrm{~b}$ in Reiss \& Marino (2001) includes both early and late sham markings. The authors are explicit about the differences between the two and provide statistical tests to differentiate them which were consistent, again, with the self-recognition hypothesis.

In addition to Reiss \& Marino (2001) there is a growing body of experimental evidence for other facets of selfawareness in dolphins. Body awareness has been demonstrated through the dolphin's ability to understand symbolic gestural references to her own body parts and the ability to use those body parts in ways (often novel) specified by the experimenter, such as touching a frisbee with her dorsal fin, raising her tail out of the water, or tossing a surfboard with her genital area (Herman et al., 2001). Also, awareness of one's own behaviours has been demonstrated through the dolphin's ability to repeat a behaviour she just performed, in response to a "repeat" command, or to perform a different behaviour if so instructed (Herman, 2002; Mercado et al., 1998, 1999). Moreover, McCowan et al. (2000) provided evidence that bottlenose dolphins anticipate, monitor, organize, and modify goal-directed behaviour on the basis of contingencies. By applying statistical tests to observations of bubble ring play in captive bottlenose dolphins McCowan et al. (2000) revealed evidence that the dolphins were monitoring the quality of their bubble rings and planning future bubble production actions based upon this information. Finally, as described earlier, knowledge awareness has been demonstrated by dolphins reporting when they were "uncertain" about discriminations they were asked to make. These findings are evidence of abstract "meta-knowledge" in dolphins (Smith et al., 1995).

\section{GONGLUSIONS}

(1) Manger (2006) concludes that his three major claims are substantiated. Here we have shown that none of these claims have merit. Furthermore, we provide substantial evidence that Manger's (2006) line of argumentation is seriously flawed.

(2) Contrary to Manger's (2006) claim, there is no evidence that a "punctuated" enlargement of the cetacean brain during the Eocene-Oligocene transition ever occurred. The fossil record clearly shows that the increase in relative brain size was primarily due to a decrease in body size and not a large increase in brain size (Marino et al., $2004 a$ ). Furthermore, the notion that this change in relative brain size was a punctuated evolutionary event is an illusion deriving from inconsistencies in the cetacean fossil record.

(3) Manger's (2006) key analysis of the relationship between ocean temperature range and brain size is fatally flawed. Much of his temperature range data are either incorrect or missing. Our re-analysis using corrected data shows that the relationship between temperature and brain size is the opposite of that claimed by Manger (2006). Furthermore, he used the metric of EQ in a statistically inappropriate manner in his analyses. When the correct metric, residual brain size, is used there is no correlation between maximum or minimum temperature, whether taken from Manger's (2006) Table 1 or corrected, and residual brain size, again, falsifying another of his central claims.

(4) There are no empirical data to support Manger's (2006) claim that REM sleep in cetaceans or any other mammals is associated with a decrease in thermogenesis. In fact, the available evidence from other species shows, once again, the opposite.

(5) Manger's (2006) interpretation of the complexity of cetacean brain organisation is not consistent with the anatomical evidence. Furthermore, at the core of his argument is his contention that cetacean brains have a glia/neuron $(\mathrm{G} / \mathrm{N})$ index that is higher than expected. We have demonstrated that the existing data do not support this claim.

(6) Manger (2006) claims there is no complex cognition in cetaceans. Here too, we show that his claims are based on a combination of erroneous information and omission of scores of peer-reviewed published studies showing otherwise. In particular, his claims about the simplicity and involuntary nature of cetacean vocalisations are simply not parsimonious with the copious amount of evidence for vocal learning and flexibility in cetaceans.

(7) Manger's approach is in direct opposition to the normal flow of logic used in scientific inquiry. It is as if his mantra was "function follows form" rather than "form 
follows function". In point of fact, given that so little is known about cetacean brain anatomy it is premature to draw firm conclusions about the functional characteristics of cetacean brains based on anatomy. Moreover, given the substantial evidence for cognitive complexity in cetaceans Manger's claim is not reasonable.

(8) In one of the last points made in Manger (2006) he states that his thermogenesis hypothesis is a "credible and testable alternative to explain actual and relative brain size..." (p. 333). We have shown that it is testable and ungrounded. Manger's (2006) thermogenesis hypothesis remains a claim in search of evidence.

\section{AGKNOWLEDGEMENTS}

Supported by the James S. McDonnell Foundation (22002078 to PRH).

Support for contributions by $L H$ and $A P$ provided by members of The Dolphin Institute, LeBurta Atherton, Terrie and Larry Henry, the Arthur M. Blank Family Foundation, and The Resort Group at Ko Olina.

Support for $D L$ provided by the Killam Trusts.

Support for $L M$ and $M U$ provided by National Science Foundation.

$L R$ was supported by a NERG Postdoctoral Fellowship (NER/I/S/2002/00632).

\section{REFERENGES}

Alföldi, P., Rubicsek, G., Cserni, G. \& Obal, F. (1990). Brain and core temperatures and peripheral vasomotion during sleep and wakefulness at various ambient temperatures in the rat. Pflugers Archive 417, 336-341.

Allman, J. M., Hakeem, A. Y. \& Watson, K. K. (2002). Two phylogenetic specializations of the human brain. Neuroscientist $\mathbf{8}$, 335-346.

Allman, J. M., Watson, K. K., Tetrault, N. A. \& Hakeem, A. Y. (2005). Intuition and autism: a possible role for Von Economo neurons. Trends in Cognitive Science 9, 367-373.

Au, W. W. L. (1993). The Sonar of Dolphins. Springer-Verlag Inc., New York.

BAIRD, R. (2000). The killer whale: foraging specializations and group hunting. In Cetacean societies: Field Studies of Whales and Dolphins (eds. J. Mannor, R. C. Connor, P. Tyack and H. Whitehead H), pp. 127-153. University of Chicago Press, Chicago.

Baker, C. S. \& Herman, L. M. (1984). Aggressive behaviour between humpback whales (Megaptera novaeangliae) wintering in Hawaiian waters. Canadian Fournal of Zoology 62, 1922-1937.

Buinkov, S. M. \& Glezer, I. I. (1968). The Human Brain in Figures and Tables: A Quantitative Handbook. Plenum Press, New York.

Bouzier-Sore, A. K., Voisin, P., Canioni, P., Magistretti, P. J. \& Pellerin, L. (2003). Lactate is a preferential oxidative energy substrate over glucose for neurons in culture. Fournal of Cerebral Blood Flow and Metabolism 23, 1298-1306.

Boyd, R. \& Richerson, P. (1985). Culture and the Evolutionary Process. Chicago University Press, Chicago.
Braslau-Schneck, S., (1994). Innovative Behaviours and Synchronization in Bottlenosed Dolphins. Unpublished master's thesis, University of Hawaii, Honolulu.

Breathnach, A. S. \& Goldby, F. (1954). The amygdaloid nuclei, hippocampus and other parts of the rhinencephalon in the porpoise (Phocoena phocoena). Fournal of Anatomy 88, 267-291.

Caldwell, M. G. \& Caldwell, D. K. (1965). Individualized whistle contours in bottle-nosed dolphins (Tursiops truncatus). Nature 207, 434-435.

Caldwell, M. C. \& Caldwell, D. K. (1966). Epimeletic (caregiving) behaviour in cetacea. In Dolphins and Porpoises. (ed. K. S. Norris), pp. 755-789. University of California Press.

Caldwell, M. C., Galdwell, D. K. \& Tyack, P. L. (1990). Review of the signature-whistle hypothesis for the Atlantic bottlenose dolphin. In The Bottlenose Dolphin. (ed. S. Leatherwood and R. R. Reeves), pp. 199-234. Academic Press, San Diego, CA.

Caputa, M. (2004). Selective brain cooling: a multiple regulatory mechanism. Fournal of Thermal Biology 29, 691-702.

Connor, R. G. (2007). Complex alliance relationships in bottlenose dolphins and a consideration of selective environments for extreme brain size evolution in mammals. Philosophical Transactions of the Royal Society: Biological Sciences 362, 587-602.

Connor, R. G. \& Norris, K. A. (1982). Are dolphins reciprocal altruists? The American Naturalist 119, 358-374.

Connor, R. C., Richards, A. F., Smolker, R. A. \& Mann, J.. (1996). Patterns of female attractiveness in Indian Ocean bottlenose dolphins. Behaviour 133, 37-69.

Connor, R. C. \& Smolker, R. A. (1996). 'Pop' goes the dolphin: a vocalization male bottlenose dolphins produce during consortships. Behaviour 133, 643-662.

Connor, R. C., Smolker, R. A., \& A. F. Richards. (1992a). Two levels of alliance formation among male bottlenose dolphins (Tursiops sp.). Proceedings of the National Academy of Sciences 89, 987-990.

Connor, R. C., Smolker, R. A. \& Richards, A. F. (1992b). Dolphin alliances and coalitions. In Coalitions and Alliances in Animals and Humans (eds. A. H. Harcourt and F. B. M. De Waal), pp. 415-443. Oxford University Press, Oxford.

Connor, R. C, Wells, R., Mann, J. \& Read, A. (2000). The bottlenose dolphin: social relationships in a fission-fusion society. In Cetacean Societies: Field Studies of Whales and Dolphins (eds. J. Mann, R. C. Connor, P. Tyack, and H. Whitehead), pp. 91-126. University of Chicago Press, Chicago.

D'Amato, M. R. (1973). Delayed matching and short-term memory in monkeys. In The Psychology of learning and motivation: Advances in Research and Theory, Vol. 7 (ed. G. H. Bower), pp. 227269. Academic Press, New York.

Dawson, W. W., Hawthorne, M. N., Jenkins, R. L. \& Goldston, R. T. (1982). Giant neural system in the inner retina and optic nerve of small whales. The Journal of Comparative Neurology 205, $1-7$.

DeConto, R. M. \& Pollard, D. (2003). Rapid Cenozoic glaciation of Antarctica induced by declining atmospheric $\mathrm{CO}_{2}$. Nature 421, 245-249.

Deecke, V. B., Ford, J. K. B. \& Spong, P. (2000). Dialect change in resident killer whales: implications for vocal learning and cultural transmission. Animal Behaviour 40: 629-638.

Deecke, V. B., Slater, P. J. B. \& Ford, J. K. B. (2002). Selective habituation shapes acoustic predator recognition in harbour seals. Nature 420, 171-173.

Delfour, F. \& Marten, K. (2001). Mirror image processing in three marine mammal species: killer whales (Orca orcinus), false 
killer whales (Pseudorca crassidens) and California sea lions (Zalophus californianus). Behavioural Processes 53, 181-190.

Ding, W., Würsig, B. \& Evans, W. E. (1995). Whistles of bottlenose dolphins: Comparisons among populations. Aquatic Mammals 21, 65-77.

Downhower, J. F. \& Blumer, L. S. (1988). Calculating just how small a whale can be. Nature 335, 675.

Dudzinski, K. M., Thomas, J. A., \& Dounze, E. (2000). Communication. In Encyclopedia of marine mammals (eds. W. F. Perrin, B. Wursig and J. G. M. Thewissen), pp. 248-268. Academic Press, New York.

Edgar, D. M. \& Fuller, C. A. (1984). Diurnal rhythms of sleep and brain temperature in the squirrel monkey. Society for Neuroscience Abstracts 10, 504.

Emery, N. (2006), Cognitive ornithology: the evolution of avian intelligence. Philosophical Transactions of the Royal Society Biological Sciences 361, 23-43.

Eriksen, N. \& Pakkenberg, B. (2007). Total neocortical cell number in the mysticete brain. The Anatomical Record 290, 83-95.

Erlanson-Albertsson, C. (2003). The role of uncoupling proteins in the regulation of metabolism. Acta Physiologica Scandinavica 178, 405-412.

Feldman, M. W. \& Laland, K. N. (1996). Gene-culture coevolutionary theory. Trends in Ecology and Evolution 11, 453-457

Felleman, D. J. \& Van Essen, D. C. (1991). Distributed hierarchical processing in the primate cerebral cortex. Cerebral Cortex 1, 1-47.

Ferrer i Cancho, R. \& Lusseau, D. (2006). Long-term correlation in the surface behaviour of dolphins. Europhysics Letters 74, $1095-1101$.

Fleischer, G. (1976). Hearing in extinct cetaceans as determined by cochlear structure. Fournal of Paleontology 50, 133-152.

ForD, J. K. B. (1991). Vocal traditions among resident killer whales (Orcinus orca) in coastal waters of British Columbia. Canadian Fournal of Zoology 69, 1454-1483.

Ford, J. K. B., Ellis, G. M. \& Balcomb, K. C. (2000). Killer Whales. University of British Columbia Press, Vancouver.

FordycE, R. E. (2002a). Oligocene archaeocetes and toothed mysticetes: Cetacea from times of transition. Geological Society of New Zealand Miscellaneous Publication, 114A, 16-17.

Fordyce, R. E. (2002b). Simocetus rayi (Odontoceti: Simocetidae) (new species, new genus, new family), a bizarre new archaic Oligocene dolphin from the eastern North Pacific. Smithsonian Contributions to Paleobiology 93, 185-222.

Fordyce, R. E. (2003a). Cetacea evolution and Eocene-Oligocene oceans revisited. In From greenhouse to icehouse. The marine EoceneOligocene transition. (ed. D. R. Prothero, L. C. Ivany, \& E. Nesbitt), pp. 154-170. Columbia University Press, New York.

FordycE, R. E. (2003b). The toothed stem-mysticete Llanocetus in the Latest Eocene of the southern Ocean. Fournal of Vertebrate Paleontology 23, 50a-5la.

Fordyce, R. E. \& Barnes, L. G. (1994). The evolutionary history of whales and dolphins. Annual Review of Earth and Planetary Sciences 22, 419-455.

Garey, L. J. \& Leuba, G. (1986). A quantitative study of neuronal and glial numerical density in the visual cortex of the bottlenose dolphin: evidence for a specialised subarea and changes with age. The Fournal of Comparative Neurology 247, 491-496.

Gazda, S. K., Connor, R. G., Edgar, R. K, \& Cox, F. (2005). A division of labor with role specialization in group-hunting bottlenose dolphins (Tursiops truncatus) off Cedar Key, Florida. Proceedings of the Royal Society of London Series B 272, 135-140.
Gihr, M. \& Pilleri, G. (1969). Hirn-Körpergewichts-Beziehungen bei Cetaceen. Investigations on Cetacea, 1, 109-126.

Gingerich, P. D. (1998). Paleobiological perspectives on Mesonychia, Archaeoceti and the origin of whales. In The emergence of whales. Evolutionary patterns in the origin of Cetacea. (ed. J. G. M. Thewissen), pp. 423-449. Plenum, New York.

Glezer, I. I., Hof, P. R., Leranth, C. \& Morgane, P. J. (1993). Calcium-binding protein-containing neuronal populations in mammalian visual cortex: a comparative study in whales, insectivores, bats, rodents, and primates. Cerebral Cortex 3, 249-272.

Glezer, I. I., Hof, P. R. \& Morgane, P. J. (1998). Comparative analysis of calcium-binding protein-immunoreactive neuronal populations in the auditory and visual systems of the bottlenose dolphin (Tursiops truncatus) and the macaque monkey (Macaca fascicularis). Fournal of Chemical Neuroanatomy 15, 203-237.

Glezer, I. I., Jacobs, M. S. \& Morgane, P. J. (1987). Ultrastructure of the blood-brain barrier in the dolphin (Stenella coeruleoalba). Brain Research 414, 205-218.

Glezer, I. I. \& Morgane, P. J. (1990). Ultrastructure of synapses and Golgi analysis of neurons in neocortex of the lateral gyrus (visual cortex) of the dolphin and pilot whale. Brain Research Bulletin 24, 401-427.

Gunderson, V. M., Rose, S. A. \& Grant-Webster, K. S. (1990). Cross-modal transfer in high- and low-risk infant pigtailed macaque monkeys. Developmental Psychology 26, 576-581.

Hakeem, A. Y., Hof, P. R., Sherwood, C. C., Switzer, R. C., Rasmussen, L. E. \& Allman, J. M. (2005). Brain of the African elephant (Loxodonta africana): neuroanatomy from magnetic resonance images. The Anatomical Record 287A, 1117-1127.

HaQ, B. U., Hardenbol, J., \& Vail, P. R. (1987). Chronology of fluctuating sea levels since the Triassic. Science 235, 11561166.

Hartline, D. K. \& Colman, D. R. (2007). Rapid conduction and the evolution of giant axons and myelinated fibers. Current Biology 17, 29-35.

Hawkins, A. \& Olszewski, J. (1957). Glia/nerve cell index for cortex of the whale. Science 126, 76-77.

Hayward, J. N. \& Baker, M. A. (1969). A comparative study of the role of the cerebral arterial blood in the regulation of brain temperature in five mammals. Brain Research 16, 417-440.

Helweg, D. A., Bauer, G. B. \& Herman, L. M. (1992). Observations of an S-shaped posture in humpback whales (Megaptera novaeangliae). Aquatic Mammals 18, 74-78.

Herman, L. M. (1975). Interference and short-term memory in the bottlenose dolphin. Animal Learning and Behaviour 3, 43-48.

Herman, L. M. (1980). Cognitive characteristics of dolphins. In Cetacean behaviour: Mechanisms and functions (ed. L. M. Herman), pp. 363-429. Wiley Interscience, New York.

Herman, L. M. (1986). Cognition and language competencies of bottlenose dolphins. In Dolphin Cognition and Behaviour: A Comparative Approach (eds. R. J. Schusterman, J. Thomas and F. G. Wood), pp. 221-251. Lawrence Erlbaum Associates, Hillsdale, New Jersey.

Herman, L. M. (1987). Receptive competencies of language trained animals. In Advances in the Study of Behaviour. Vol. 17 (eds. J. S. Rosenblatt, C. Beer, M. C. Busnel and P. J. B. Slater), pp. 160. Academic Press, Petaluma, CA.

Herman, L. M. (2002). Vocal, social, and self-imitation by bottlenose dolphins. In Imitation in animals and artifacts (eds. K. Dautenhahn and C. L. Nehaniv), pp. 63-108. MIT Press, Cambridge, Mass. 
Herman, L. M. (2006). Intelligence and rational behaviour in the bottlenose dolphin. In Rational animals? (eds. S. Hurley and M. Nudds), pp. 439-468. Oxford University Press, Oxford.

Herman, L. M., Abichandani, S. L., ElhajJ, A. N., Herman, E. Y. K., Sanchez, J. L., \& PAck, A. A. (1999). Dolphins (Tursiops truncatus) comprehend the referential character of the human pointing gesture. Fournal of Comparative Psychology 113, 1-18.

Herman, L. M. \& Forestell, P. H. (1985). Reporting presence or absence of named objects by a language-trained dolphin. Neuroscience and Biobehavioural Reviews 9, 667-691.

Herman, L. M. \& Gordon, J. A. (1974). Auditory delayed matching in the bottlenose dolphin. Fournal of the Experimental Analysis of Behaviour 21, 19-26.

Herman, L. M., Hovancik, J. R., Gory, J. D. \& Bradshaw, G. L. (1989). Generalization of visual matching by a bottlenose dolphin (Tursiops trncatus): Evidence for invariance of cognitive performance with visual or auditory materials. Fournal of Experimental Psychology: Animal Behaviour Processes 15, 124-136.

Herman, L. M., KuczaJ, S. A. II \& Holder, M. D. (1993a). Responses to anomalous gestural sequences by a languagetrained dolphin: evidence for processing of semantic relations and syntactic information. Fournal of Experimental Psychology: General 122, $184-194$.

Herman, L. M., Matus, D. S., Herman, E. Y. K., Ivancic, M., \& PAck, A. A. (2001). The bottlenose dolphin's (Tursiops truncatus) understanding of gestures as symbolic representations of its body parts. Animal Learning \& Behaviour 29, 250-264.

Herman, L. M., Morrel-Samuels, P. \& Pack, A. A. (1990). Bottlenosed dolphin and human recognition of veridical and degraded video displays of an artificial gestural language. Fournal of Experimental Psychology: General 119, 215-230.

Herman, L. M. \& PACK, A. A. (2001). Laboratory evidence for cultural transmission mechanisms. Commentary on Rendell and Whitehead. Behavioural and Brain Sciences 24, 335-336.

Herman, L. M., Pack, A. A. \& Hoffmann-Kuhnt, M. (1998). Seeing through sound: Dolphins perceive the spatial structure of objects through echolocation. Fournal of Comparative Psychology 112, 292-305.

Herman, L. M., Pack A. A. \& Morrel-Samuels, P. (1993b). Representational and conceptual skills of dolphins. In Language and Communication: Comparative Perspectives (eds. H. R. Roitblat, L. M. Herman and P. Nachtigall), pp. 273-298. Lawrence Erlbaum, Hillsdale, New Jersey.

Herman, L. M., Pack, A. A. \& Wood, A. M. (1994). Bottlenosed dolphins can generalize rules and develop abstract concepts. Marine Mammal Science 10, 70-80.

Herman, L., M., Richards, D. G., \& Wolz, J. P. (1984). Comprehension of sentences by bottlenose dolphins. Cognition 16, 129-219.

Herman, L. M. \& Tavolga, W. N. (1980). The communication systems of cetaceans. In Cetacean Behaviour: Mechanisms and Functions (ed. L. M. Herman), pp. 149-209. Wiley Interscience, New York.

Herman, L. M. \& Thompson, R. K. R. (1982). Symbolic, identity, and probe delayed matching of sounds by the bottlenose dolphin. Animal Learning and Behaviour 10, 22-34.

Herzing, D. L. (2000). Acoustic and social behaviour of wild dolphins: implications for a sound society. In Hearing by Whales and Dolphins. (eds. W. L. A. N. Popper and R. R. Fay), pp. 225272. Springer-Verlag Press, New York.

Heyning, J. E. \& Mead, J. G. (1997). Thermoregulation in the mouths of feeding gray whales. Science 278, 1138-1139.
Hof, P. R., Chanis, R. \& Marino, L. (2005). Cortical complexity in cetacean brains. The Anatomical Record 287, 1142-1152.

Hof, P. R., Glezer, I. I., Archin, N., Janssen, W. G., Morgane, P. J. \& Morrison, J. H. (1992). The primary auditory cortex in cetacean and human brain: a comparative analysis of neurofilament protein-containing pyramidal neurons. Neuroscience Letters 146, 91-95.

Hof, P. R., Glezer, I. I., Conde, F., FlagG, R. A., Rubin, M. B., Nimchinsky, E., Vogt, B. A. \& Weisenhorn, D. M. (1999). Cellular distribution of the calcium-binding proteins parvalbumin, calbindin, and calretinin in the neocortex of mammals: phylogenetic and developmental patterns. Fournal of Chemical Neuroanatomy 16, 77-116.

Hof, P. R., Glezer, I. I., Nimchinsky, E. A. \& Erwin, J. M. (2000). Neurochemical and cellular specializations in the mammalian neocortex reflect phylogenetic relationships: Evidence from primates, cetaceans, and artiodactyls. Brain Behaviour and Evolution 55, 300-310.

Hof, P. R. \& Sherwood, C. (2005). Morphomolecular neuronal phenotypes in the neocortex reflect phylogenetic relationships among certain mammalian orders. The Anatomical Record 287A, 1153-1163.

Hof, P. R. \& VAn der Gucht, E. (2007). The structure of the cerebral cortex of the humpback whale, Megaptera novaeangliae (Cetacea, Mysticeti, Balaenopteridae). The Anatomical Record 290, 1-31.

Hooper, S. L., Reiss, D. R., Carter, M. \& McCowan, B. (2006). Importance of contextual saliency on vocal imitation by bottlenose dolphins. International fournal of Comparative Psychology 19, 116-128.

Humphrey, N. K. (1976). The social function of intellect. In Growing Points in Ethology: (eds. P. P. G. Bateson and R. A. Hinde), pp. 303-317. Cambridge University Press, Cambridge, UK.

Innes, S. \& Lavigne, D. M. (1989). Size of aquatic endotherms. Nature 341, 92.

Iverson, S. J. (2002). Blubber. In Encyclopedia of Marine Mammals (eds. W. F. Perrin, B. Wursig, and J. G. M. Thewissen), pp. 107112. Academic Press, New York.

Jahkkola, K., Fellner, W., Erb, L., Rodriguez, M. \& Guarino, E. (2005). Understanding of the concept of numerically "less" by bottlenose dolphins (Tursiops truncatus). Fournal of Comparative Psychology 119, 296-303.

Jacobs, M. S., Galaburda, A. M., MaFarland, W. L. \& Morgane, P. J. (1984). The insular formation of the dolphin brain: quantitative cytoarchitectonic study of the insular component of the limbic lobe. Fournal of Comparative Neurology 225, 396-432.

Jacobs, M. S., McFarland, W. L. \& Morgane, P. J. (1979). The anatomy of the brain of the bottlenose dolphin (Tursiops truncatus). Rhinic lobe (rhinencephalon): the archicortex. Brain Research Bulletin 4 (Suppl. 1), 1-108.

JANIK, V. M. (1999). Origins and implications of vocal learning in bottlenose dolphins. In Mammalian Social Learning: Comparative and Ecological Perspectives (eds. H. O. Box and K. R. Gibson), pp. 308326. Cambridge University Press, Cambridge.

JANIK, V. M. (2000). Food-related bray calls in wild bottlenose dolphins (Tursiops truncatus). Proceedings of the Royal Society of London, B - Biological Sciences 267, 923-927.

Janik, V. M., Sayigh, L. S. \& Well, R. S. (2006). Signature whistle shape conveys identity information to bottlenose dolphins. Proceedings of the National Academy of Sciences of the United States of America 103, 8293-8297. 
Janik, V. M. \& Slater, P. J. B. (1997). Vocal learning in mammals. Advances in the Study of Behaviour 26, 59-99.

Janik, V. M. \& Slater, P. J. B. (1998). Context-specific use suggests that bottlenose dolphin signature whistles are cohesion calls. Animal Behaviour 56, 829-838.

Jerison, H. J. (1973). Evolution of the Brain and Intelligence. Academic Press, New York.

Jerison, H. J. (1986). The perceptual world of dolphins. In Dolphin Cognition and Behaviour: A Comparative Approach (eds. R. J. Schusterman, J. A. Thomas and F. G. Wood), pp. 141-166, Lawrence Erlbaum, New Jersey.

Kawamura, H. \& Sawyer, C. H. (1965). Elevation in brain temperature during paradoxical sleep. Science 150, 912-913.

Kawamura, H., Whitmeyer, D. I. \& Sawyer, C. H. (1966). Temperature changes in the rabbit brain during paradoxical sleep. Electroencephalography and Clinical Neurophysiology 21, 469-477.

Kilian, A., Yaman, S., Von Fersen, L. \& Gunturkun, O. (2003). A bottlenose dolphin discriminates visual stimuli differing in numerosity. Learning and Behaviour 31, 133-142.

Kraus, C. \& Pilleri, G. (1969). Quantitative Untersuchungen über die Grosshirnrinde der Cetaceen. Investigations on Cetacea $\mathbf{1}$, 127-150.

Kruttzen, M., Mann, J., Heithaus, M. R., Connor, W. C., Bejder, L. \& Sherwin, W. B. (2005). Cultural transmission of tool use in bottlenose dolphins. Proceedings of the National Academy of Sciences USA 102, 8939-8943.

Kumar, S. \& Blair Hedges, S. (1998). A molecular timescale for vertebrate evolution. Nature 392, 917-920.

Lilly, J. C. (1967). The Mind of the Dolphin: A Nonhuman Intelligence. Doubleday, New York.

Lindberg, D. R. \& Pyenson, N. D. (2007). Things that go bump in the night: evolutionary between cephalopods and cetaceans in the Tertiary. Lethaia 40, 335-343.

Lusseau, D. (2006). Why do dolphins jump? Interpreting the behavioural repertoire of bottlenose dolphins (Tursiops sp.) in Doubtful Sound, New Zealand. Behavioural Processes 73, 257-265.

Lusseau, D. (2007). Evidence for social role in a dolphin social network. Evolutionary Ecology 21, 357-366.

Lyamin, O. I., Shpak, O. V., Nazarenko, E. A. \& Mukhametov, L. M. (2002). Muscle jerks during behavioural sleep in a beluga whale (Delphinapterus leucas L.). Physiology and Behaviour 76, 265-270.

Lyle, M., Gibbs, S., Moore, T. C. \& Rea, D. K. (2007). Late Oligocene initiation of the Antarctic Circumpolar Current: Evidence from the South Pacific. Geology 35, 691-694.

Madsen, C. \& Herman L. M. (1980). Social and ecological correlates of cetacean vision and visual appearance. In Cetacean behaviour: Mechanisms and functions (ed. L. M. Herman), pp. 101148. Wiley Interscience, New York.

Magistretti, P. J., Hof, P. R. \& Celio, M. R. (1987). Noradrenergic sub-sensitivity in the cerebral cortex of the tottering mouse, a spontaneously epileptic mutant. Brain Research 403, 181-185.

Magistretti, P. J. \& Pellerin, L. (1999). Astrocytes couple synaptic activity to glucose utilization in the brain. News in Physiological Sciences 14, 177-182.

Manger, P. R. (2006). An examination of cetacean brain structure with a novel hypothesis correlating thermogenesis to the evolution of a big brain. Biological Reviews of the Cambridge Philosophical Society 81, 293-338.

Manger, P. R., Sum, M., Szymansky, M., Ridgway, SW. \& KRUBitzer, L. (1998). Modular subdivision of dolphin insular cortex: does evolutionary history repeat itself? Fournal of Cognitive Neuroscience 10, 153-166.

Mao, W., Yu, X. X., Zhong, A., Li, W., Brush, J., Sherwood, S. W., AdAms, S. H. \& PAN, G. (1999). UCP4, a novel brainspecific mitochondrial protein that reduces membrane potential in mammalian cells. Federation of European Biochemical Societies Letters 443, 326-330.

Marcoux, M., Rendell, L. \& Whitehead, H. (2007). Indications of fitness differences among vocal clans of sperm whales. Behavioural Ecology and Sociobiology 61, 1093-1098.

MARINO, L. (1998). A comparison of encephalization between odontocete cetaceans and anthropoid primates. Brain, Behaviour and Evolution 51, 230-238.

Marino, L. (2002). Convergence in complex cognitive abilities in cetaceans and primates. Brain, Behaviour and Evolution 59, 21-32.

Marino, L., MaShea, D. \& Uhen, M. D. (2004a). The origin and evolution of large brains in toothed whales. The Anatomical Record 281A, 1247-1255.

Marino, L., Reiss, D., Gallup Jr., G. G. (1994). Mirror selfrecognition in bottlenose dolphins: Implications for comparative investigations of highly dissimilar species. In Self Awareness in Animals and Humans: Developmental Perspectives. (ed. S. Parker, R. Mitchell and M. Boccia), pp. 380-391. Cambridge University Press, New York.

Marino, L., Sherwood, G. C., Tang, G. Y., Delman, B. N., Naidich, T.P., Johnson, J. I. \& Hof, P. R. (2004b). Neuroanatomy of the killer whale (Orcinus orca) from Magnetic Resonance Imaging. The Anatomical Record 281A, 1256-1263.

Marino, L., Sol, D., Toren, K. \& Lefebvre, L. (2006). Does diving limit brain size in cetaceans? Marine Mammal Science 22, $413-425$

Marten, K. \& Psarakos, S. (1994). Evidence of self-awareness in the bottlenose dolphin (Tursiops truncatus). In Self Awareness in Animals and Humans: Developmental Perspectives. (ed. S. Parker, R. Mitchell and M. Boccia), pp. 261-279. Cambridge University Press, New York.

Matthews, R. K. \& Poore, W. Z. (1980). Tertiary $\partial 18$ O record and glacio-eustatic sea-level fluctuations. Geology 8, 501-504.

McGowan, B., Doyle, L. R. \& Hanser, S.F. (2002). Using information theory to assess the diversity, complexity and development of communicative repertoires. Fournal of Comparative Psychology 116 166-172.

McCowan, B., Hanser, S.F. \& Doyle, L. R. (1999). Quantitative tools for comparing animal communication systems: information theory applied to bottlenose dolphin whistle repertoires. Animal Behaviour 57, 409-419

McCowan, B., Marino, L., Vance, E., Walke, L. \& Reiss, D. (2000). Bubble ring play of bottlenose dolphins: Implications for cognition. Fournal of Comparative Psychology 114, 98-106.

McCowan, B. \& ReIss, D. (1995a). Quantitative comparison of whistle repertoires from captive adult bottlenose dolphins (Delphinidae Tursiops truncatus): a re-evaluation of the signature whistle hypothesis. Ethology 100, 194-209.

McCowan, B. \& Reiss, D. (1995b). Whistle contour development in captive-born infant bottlenose dolphins: a role for learning? Fournal of Comparative Psychology 109, 242-260.

McCowan, B. \& Reiss, D. (2001). The fallacy of 'signature whistles' in bottlenose dolphins: a comparative perspective of 'signature information' in animal vocalizations. Animal Behaviour 62, 1151-1162.

McFarland, W. L., Jacobs, M. S. \& Morgane, P. J. (1979). Blood supply to the brain of the dolphin, Tursiops truncatus, with 
comparative observations on special aspects of the cerebrovascular supply of other vertebrates. Neuroscience and Biobehavioural Reviews 3(Suppl. 1), 1-93.

McGrew, W. C. (2003). Ten dispatches from the chimpanzee culture wars. In Animal social complexity. Intelligence, culture, and individualized societies, (eds. F. B. M. de Waal, and P. L. Tyack), pp. 419-439. Harvard University Press, Cambridge, MA.

Mercado, III, E. M., Killebrew, D. A., Pack, A. A., Macha, IV, B. \& Herman, L. M. (2000). Generalization of same-different classification abilities in bottlenose dolphins. Behavioural Processes 50, 79-94.

Mercado III, E., Murray, S. O., Uyeyama, W. K., Pack, A. A. \& Herman, L. M. (1998). Memory for recent actions in the bottlenose dolphin (Tursiops trncatus): repetition of arbitrary behaviours using an abstract rule. Animal Learning and Behaviour 26, 210-218.

Mercado III, E., Uyeyama, R. K., Pack, A. A. \& Herman, L. M. (1999). Memory for action events in the bottlenose dolphin. Animal Cognition 2, 17-25.

Miller, P. J. O. \& BaIn, D. E. (2000). Within-pod variation in the sound production of a pod of killer whales, Orcinus orca. Animal Behaviour 60, 617-628.

Millien, V., Lyons, S.K., Olson, L., Smith, F. A., Wilson, A. B. \& Yom-Tov, Y. (2006). Ecophenotypic variation in the context of global climate change: revisiting the rules. Ecology Letters 9, 853-869.

Morgane, P. J., Glezer, I. I. \& Jacobs, M. S. (1988). The lateral gyrus (visual cortex) of the dolphin: an image analysis study. Journal of Comparative Neurology 273, 3-25.

Morgane, P. J., Jacobs, M. S. \& MaFarland, W. L. (1980). The anatomy of the brain of the bottlenose dolphin (Tursiops truncatus). Surface configuration of the telencephalon of the bottlenose dolphin with comparative anatomical observations in four other cetacean species. Brain Research Bulletin 5 (Suppl 3), 1-107.

Muknametov, L. M. (1995). Paradoxical sleep peculiarities in aquatic mammals. Sleep Research 24A, 202.

NaKaJima, M. (1961). The study of the rete mirabile of the cetacea centered around Grampidelphis griseus and Tursiops truncatus. TohoIgakukai-Zasshi 8, 1611-1624 (in Japanese).

Nimchinsky, E. A., Gilissen, E., Allman, J. M., Perl, D. P., Erwin, J. M., \& Hof, P. R. (1999). A neuronal morphologic type unique to humans and great apes. Proceedings of the National Academy of Sciences 96, 5268-5273.

Nimchinsky, E. A., Vogt, B. A., Morrison, J. H. \& Hof, P. R. (1995). Spindle neurons of the human anterior cingulate cortex. Fournal of Comparative Neurology 355, 27-37.

Noad, M. J., Cato, D. H., Bryden, M. M., Jenner, M. -N. \& Jenner, K. C. S. (2000). Cultural revolution in whale songs. Nature 408, 537.

Oelschlager, H. A. \& Oelschlager, J. S. (2002). Brains. In Encyclopedia of Marine Mammals (eds. W. F. Perrin, B. Wursig and H. Thewissen), pp. 133-158. Academic Press, San Diego, CA.

Ono, M., Kublik, S. \& Abernathey, C. D. (1990). Atlas of the Cerebral Sulci. Thieme Medical Publishers, New York.

Pack, A. A. \& Herman, L. M. (1995). Sensory integration in the bottlenose dolphin: Immediate recognition of complex shapes across the senses of echolocation and vision. Fournal of the Acoustical Society of America 98, 722-733.

Pack, A. A. \& Herman, L. M. (2004). Dolphins (Tursiops truncatus) comprehend the referent of both static and dynamic human gazing and pointing in an object choice task. Fournal of Comparative Psychology 118, 160-171.
Pack, A. A. \& Herman, L. M. (2006). Dolphin social cognition and joint attention: Our current understanding. Aquatic Mammals 32, 443-460.

Pack, A. A. \& Herman, L. M. (2007). The dolphin's (Tursiops truncatus) understanding of human gaze and pointing: Knowing what and where. Fournal of Comparative Psychology 121, 34-45.

Pack, A. A., Herman, L. M., Hoffmann-Kuhnt, M. \& Branstetter, B. K. (2002). The object behind the echo: Dolphins (Tursiops truncatus) perceive object shape globally through echolocation. Behavioural Processes 58, 1-26.

Palca, J. W., Walker, J. M. \& Berger, R. J. (1981). Tympanic temperature and REM sleep in cold-exposed humans. Acta Universitatis Carolinae-Biologica, 225-227.

Parmeggiani, P. L., Zamboni, G., Perez, E. \& Lenzi, P. (1984). Hypothalamic temperature during desynchronized sleep. Experimental Brain Research 54, 315-320.

Pavio, A., \& Begg, I. (1981). Psychology and Language. Prentice-Hall, New Jersey.

Pellerin, L. (2003). Lactate as a pivotal element in neuron-glia metabolic cooperation. Neurochemistry International 43, 331-338.

Pellerin, L. \& Magistretti, P. J. (2004). Neuroenergetics: calling upon astrocytes to satisfy hungry neurons. Neuroscientist 10, 53-62.

Peters, A., Palay, S.L. \& Webster, H. (1991). The Fine Structure of the Nervous System. Oxford University Press, Oxford, UK.

Pfeiffer, C. J. \& Kinkead, T. P. (1990). Microanatomy of retia mirabilia of Bowhead whale foramen magnum and mandibular foramen. Acta Anatomica 139, 141-150.

Poth, C., Fung, C., Gunturkun, O. Ridgway, S.H. \& OelschlAGER, H. H. (2005). Neuron numbers in sensory cortices of five delphinids compared to a physeterid, the pigmy sperm whale. Brain Research Bulletin 66, 357-360.

Pritz-Hohmeier, S., Hartig, W., Behrmann, G. \& Reichenbach, A. (1994). Immunocytochemical demonstration of astrocytes and microglia in the whale brain. Neuroscience Letters 167, 59-62.

Prothero, D. R., Ivany, L. C. \& Nesbitt, E. A. (2003). Pacific Coast Eocene-Oligocene Marine Chronostratigraphy: A Review and an Update, Columbia University Press, New York.

Pryor, K., HaAg, R. \& O'Reilly, J. (1969). The creative porpoise: Training for novel behaviour. Fournal of the Experimental Analysis of Behaviour 12, 653-661.

Puente, A. E., \& Dewsbury, D. A. (1976). Courtship and copulatory behaviour of bottlenose dolphins (Tursiops truncatus). Cetology 21, 1-9.

Reeves, W. R., Stewart, B. S., Clapham, P. J. \& Powell, J. A. (2002). National Audobon Society Guide to Marine Mammals of the World. Alfred A. Knopf, New York.

Reichenbach, A. (1989). Glia:neuron index: review and hypothesis to account for different values in various mammals. Glia 2, 71-77.

ReIsIne, T. (1981). Adaptive changes in catecholamine receptors in the central nervous system. Neuroscience 6, 1471-1502.

Reiss, D. \& Marino, L. (2001). Self-recognition in the bottlenose dolphin: A case of cognitive convergence. Proceedings of the National Academy of Sciences USA 98, 5937-5942.

Reiss, D. \& McCowan, B. (1993). Spontaneous vocal mimicry and production by bottlenose dolphins (Tursiops truncatus): Evidence for vocal learning. Fournal of Comparative Psychology 107, 301-312.

Ren, J. Q., Aika, Y., Heizmann, G. W. \& Kosaka, T. (1992). Quantitative analysis of neurons and glial cells in the rat somatosensory cortex, with special reference to GABAergic neurons and parvalbumin-containing neurons. Experimental Brain Research 92, 1-14. 
Rendell, L. E. \& Whitehead, H. (2001). Culture in whales and dolphins. Behavioural and Brain Sciences 24, 309-324.

Rendell, L. E. \& Whitehead, H. (2003). Vocal clans in sperm whales (Physeter macrocephalus). Proceedings of the Royal Society of London B - Biological Sciences 270, 225-231.

Richards, D. G. (1986). Dolphin vocal mimicry and vocal object labelling. In Dolphin Cognition and Behaviour: A Comparative Approach. (eds. W. J. Schusterman, J. A. Thomas and F. G. Wood), pp. 273-288. Lawrence Erlbaum, Hillsdale, New Jersey.

Richards, D., Wolz, J. \& Herman, L. M. (1984). Vocal mimicry of computer-generated sounds and vocal labeling of objects by a bottlenose dolphin, Tursiops truncatus. Fournal of Comparative Psychology 98, 10-28.

RidgwaY, S.H. (1986). Physiological observations on dolphin brains. In Dolphin Cognition and Behaviour: A Comparative Approach (eds. R. J. Schusterman, J. A. Thomas and F. G. Wood), pp 3159. Lawrence Erlbaum, New Jersey.

Rommel, S. A., Pabst, A., Mclellan, W. A., Mead, J. G. \& Potter, C. W. (1992). Anatomical evidence for a countercurrent heat exchanger associated with dolphin testes. The Anatomical Record 232:1, 150-156

Rommel, S. A. \& Caplan, H. (2003). Vascular adaptation for heat conservation in the tail of the Florida manatees (Trichecus manatus latirostris). Journal of Anatomy 202, 343-353.

Rommel, S. A., Early, G. A., Matassa, K. A., Pabst, D. A. \& McLellan, W. A. (1995). Venous structures associated with thermoregulation of phocid seal reproductive organs. The Anatomical Record 243, 390-402.

Rose, S. A. \& Wallace, I. F. (1985). Cross-modal and intra-modal transfer as predictors of mental development in full-term and preterm infants. Developmental Psychology 21, 949-962.

Salamy, K. A. \& Zachos, J. C. (1999). Latest Eocene-Early Oligocene climate change and Southern Ocean fertility: inferences from sediment accumulation and stable isotope data. Palaeogeography, Palaeoclimatology and Palaeoecology 145 (1-3), 61-77.

Sanchez-Abarca, L. I., Tabernero, A. \& Medina, J. M. (2001). Oligodendrocytes use lactate as a source of energy and as a precursor of lipids. Glia 36, 321-329.

Savage-Rumbaugh, E. S., Murphy, J., Sevcik, R. A., Brakke, K. E., Williams, S.L. \& Rumbaugh, D. M. (1993). Monographs of the Society for Research and Child Development, serial no. 233, 58, nos. 3-4.

Sayigh, L. S., Tyack, P. L., Wells, R. S. \& Scott, M. D. (1990). Signature whistles of free-ranging bottlenose dolphins, Tursiops truncatus: stability and mother-offspring comparisons. Behavioural Ecology and Sociobiology 26, 247-260.

Sayigh, L. S., Tyack, P. L., Wells, R. S., Solows, A. R., Scott, M. D. \& IRvine, A. B. (1999). Individual recognition in wild bottlenose dolphins: a field test using playback experiments. Animal Behaviour 57, 41-50.

Scannell, J. W., Blakemore, G. \& Young, M. P. (1995). Analysis of connectivity in the cat cerebral cortex. Fournal of Neuroscience 15, 1463-1483.

Schmidek, W. R., Zachariassen, K. E. \& Hammel, H. T. (1983). Total calorimetric measurement in the rat: influences of the sleep-wake cycle and of environmental temperature. Brain Research 288, 261-271.

Scholander, P. F. \& Schevill, W. E. (1955). Counter-current vascular heat exchange in the fins of whales. Fournal of Applied Physiology 8, 279-282.

Schwartz, J. C., Constentin, J., Martres, M. P., Protais, P. \& BAUdRY, M. (1978). Modulation of receptors mechanism in the
CNS: hyper- and hyposensitivity to catecholamines. Neuropharmacology 17, 665-685.

Slater, P. J. B. (1986). The cultural transmission of bird song. Trends in Ecology and Evolution 1, 94-97.

SlijPer, E. J. (1936). Die Cetacean Vergleichend - Anatomisch und Systematisch, Capita Zoologica. Martenus Nijhoff, The Hague pp. 7, 82-96, 102-103, 162-170, 346-348.

SLIJPER, E. J. (1958). On the vascular system of cetacea. $15^{\text {th }}$ International Congress of Zoology, Section III, paper \#38, 1-3.

Smith, R. M. \& Hanna, J. M. (1975). Skinfolds and resting heat loss in cold air and water - temperature equivalence. Fournal of Applied Physiology 39, 93-102.

Smith, J. D., Schull, J., Strote, J., McGee, K., Egnor, R. \& Erb, L. (1995). The uncertain response in the bottlenose dolphin (Tursiops truncatus). Fournal of Experimental Psychology: General 124, 391-408.

Smolker, R. A., Mann, J. \& Smuts, B. B. (1993). Use of signature whistles during separations and reunions by wild bottlenose dolphin mothers and infants. Behavioural Ecology and Sociobiology 33, 393-402.

Stafford, K. M., Nieukirk, S.L. \& Fox, C. G. (2001). Geographic and seasonal variation of blue whale calls in the North Pacific. Journal of Cetacean Research and Management 3, 65-76.

Stolzenburg, J. U., Reichenbach, A. \& Neumann, M. (1989). Size and density of glial and neuronal cells within the cerebral neocortex of various insectivorian species. Glia 2, 78-84.

Stone, E. A. \& Ariano, M. A. (1989). Are glial cells target of the central noradrenergic system? A review of the evidence. Brain Research Reviews 14, 297-309.

Sutin, J. \& Minneman, K. P. (1985). Alpha 1- and beta-adrenergic receptors are co-regulated during both noradrenergic denervation and hyperinnervation. Neuroscience 14, 973-980.

Tavolga, M. G. \& Essapian, F. S. (1957). The behaviour of the bottlenose dolphin: pregnancy, parturition, and mother-infant behaviour. Zoology 42, 11-31.

Thompson, R. K. R. \& Herman, L. M. (1977). Memory for lists of sounds by the bottlenose dolphin: Convergence of memory processes with humans? Science 195, 501-503.

Thompson, R. K.R. \& Herman, L. M. (1981). Auditory delayed discriminations by the dolphin: Nonequivalence with delayed matching performance. Animal Learning and Behaviour 9, 9-15.

Tower, D. B. (1954). Structural and functional organisation of mammalian cerebral cortex: the correlation of neuron density with brain size. Cortical neuron density in the fin whale (Balaenoptera physalus) with a note on the cortical neuron density in the Indian elephant. Fournal of Comparative Neurology 101, 19-51.

Tschudin, A., Call, J., Dunbar, R. I. M., Harris, G. \& Van der ELST, C. (2001). Comprehension of signs by dolphins (Tursiops truncatus). Fournal of Comparative Psychology 115, 100-105.

Tyack, P. L. (1986). Whistle repertoires of two bottlenose dolphins, Tursiops truncatus: mimicry of signature whistles? Behavioural Ecology and Sociobiology 18, 251-257.

Tyack, P. L. (1997). Development and social functions of signature whistles in bottlenose dolphins Tursiops truncatus. Bioacoustics $\mathbf{8}$, 21-46.

Tyack, P. L. \& Sayigh, L. S. (1997). Vocal learning in cetaceans. In Social Influences on Vocal Development. (eds. G. T. Snowdon and M. Hausberger), pp. 208-233. Cambridge University Press, Cambridge.

TYACK, P. L. (2000). Functional aspects of cetacean communication. In: Cetacean Societies: Field Studies of Dolphins and Whales. (eds. J. Mann, W. C. Connor, P. L. Tyack and H. Whitehead), pp. 270-307. University of Chicago Press, Chicago. 
Uhen, M. D. (2004). Form, Function, and Anatomy of Dorudon atrox (Mammalia, Cetacea): An Archaeocete from the Middle to Late Eocene of Egypt. The University of Michigan Museum of Paleontology Papers on Paleontology, 34, 1-222.

Uhen, M. D. \& Gingerich, P. D. (2001). A new species of dorudontine (Archaeoceti, Cetacea) from the Eocene of South Carolina. Marine Mammal Science 17, 1-34.

Uhen, M. D. \& Pyenson, N. D. (2007). Diversity estimates, biases, and historiographic effects: resolving cetacean diversity the Tertiary. Palaeontologica electronica 10 (2), 11A [1-22]. conservation.

Waugh, N. C. \& Norman, D. A. (1965). Primate memory. Psychological Review 72, 89-104.

WeHR, T. A. (1992). A brain-warming function for REM sleep. Neuroscience and Biobehavioural Reviews 16, 379-397.

Whitmore, F. C. JR. (1994). Neogene climate change and the emergence of the modern whale fauna of the North Atlantic Ocean Proceedings of the San Diego Society of Natural History 29, 223-227.

Wilson, E. O. (1975). Sociobiology: The New Synthesis. Belknap Press, Cambridge, MA.

Wood, F. G. (1973). Marine Mammals and Man: The Navy's Porpoises and Sea Lions. Luce, Washington, D.C.

Wood, F. G. \& Evans, W. E. (1980). Adaptiveness and ecology of echolocation in toothed whales. In Animal sonar systems (eds. W. Busnel and J. Fish), pp. 381-426, Plenum, New York.

Xitco, M. J., JR, (1988). Mimicry of modeled behaviours by bottlenose dolphins. Unpublished Master's Thesis, University of Hawaii, Honolulu.
Xitco, M. J. JR, Gory, J. D. \& Kuczaj II, S. A. (2001). Spontaneous pointing by bottlenose dolphins (Tursiops truncatus). Animal Cognition 4, 115-123.

Xitco, J. J. JR., Gory, J. D. \& Kuczaj II, S. A. (2004). Dolphin pointing is linked to the attentional behaviour of a receiver. Animal Cognition 7, 231-238.

Yu, X. X., Mao, W., Zhong, A., Schow, P., Brush, J., Sherwood, S. W., AdAms, S. H. \& PAN, G. (2000). Characterization of novel $\mathrm{UCP} 5 / \mathrm{BMCP} 1$ isoforms and differential regulation of UCP4 and UCP5 expression through dietary or temperature manipulation. The Federation of American Societies for Experimental Biology fournal 14, 1611-1618.

YuRK, H. (2003). Do killer whales have culture? In Animal social complexity: intelligence, culture, and individualized societies. (eds. F. B. M. de Waal and P. L. Tyack), pp. 465 -467. Harvard University Press, Cambridge, MA.

Yurk, H., Barrett-Lennard, L., Ford, J. K. B. \& Matkin, G. O. (2002). Cultural transmission within maternal lineages: Vocal clans in resident killer whales in southern Alaska. Animal Behaviour 63, 1103-1119.

Zachos, J., Pagani, M., Sloan, L., Thomas, E. \& Billups, K. (2001). Trends, rhythms, and abberations in global climate 65 Ma to present. Science 292, 686-693.

Zenker, Q. \& KubIK, S. (1996). Brain cooling in humans anatomical considerations. Anatomy and Embryology 193, 1-13.

Zola-Morgan, S. \& Souire, L. R. (1993). Neuroanatomy of memory. Annual Reviews of Neuroscience 16, 547-563. 